Review

\title{
Interorganellar calcium signaling in the regulation of cell metabolism: A cancer perspective
}

\author{
Alessandro Rimessi ${ }^{\mathrm{a}, 1, *}$, Gaia Pedriali ${ }^{\mathrm{a}, 1}$, Bianca Vezzani ${ }^{\mathrm{a}, 1}$, Anna Tarocco ${ }^{\mathrm{a}, \mathrm{b}}$, Saverio Marchi ${ }^{\mathrm{c}}$, \\ Mariusz R. Wieckowski ${ }^{\mathrm{d}}$, Carlotta Giorgi ${ }^{\mathrm{a}}$, Paolo Pinton ${ }^{\mathrm{a}, \mathrm{e}, *}$ \\ ${ }^{a}$ Dept. of Morphology, Surgery and Experimental Medicine, Section of Pathology, Oncology and Experimental Biology and Laboratory for Technologies of Advanced \\ Therapies (LTTA), University of Ferrara, 44121 Ferrara, Italy \\ ${ }^{\mathrm{b}}$ Neonatal Intensive Care Unit, University Hospital S. Anna Ferrara, 44124 Ferrara, Italy \\ ${ }^{\mathrm{c}}$ Dept. of Clinical and Molecular Sciences, Polytechnical University of Marche, 60126 Ancona, Italy \\ ${ }^{\mathrm{d}}$ Nencki Institute of Experimental Biology, 02-093 Warsaw, Poland \\ e Maria Cecilia Hospital, GVM Care \& Research, 48033 Cotignola, Ravenna, Italy
}

\section{A R T I C L E I N F O}

\section{Keywords:}

Interorganellar communication

$\mathrm{Ca} 2+$ signaling

Metabolism

Cancer

\begin{abstract}
A B S T R A C T
Organelles were originally considered to be individual cellular compartments with a defined organization and function. However, recent studies revealed that organelles deeply communicate within each other via $\mathrm{Ca}^{2+}$ exchange. This communication, mediated by specialized membrane regions in close apposition between two organelles, regulate cellular functions, including metabolism and cell fate decisions. Advances in microscopy techniques, molecular biology and biochemistry have increased our understanding of these interorganelle platforms. Research findings suggest that interorganellar $\mathrm{Ca}^{2+}$ signaling, which is altered in cancer, influences tumorigenesis and tumor progression by controlling cell death programs and metabolism.

Here, we summarize the available data on the existence and composition of interorganelle platforms connecting the endoplasmic reticulum with mitochondria, the plasma membrane, or endolysosomes. Finally, we provide a timely overview of the potential function of interorganellar $\mathrm{Ca}^{2+}$ signaling in maintaining cellular homeostasis.
\end{abstract}

\section{Introduction}

Intracellular communication among cellular compartments is carried out by specialized molecular hubs, which are frequently situated in specific membrane domains, to regulate important cellular processes, including metabolism. For example, $\mathrm{Ca}^{2+}$ communication between organelles is a widespread phenomenon that involves many, if not all, organelles [1].

Interorganellar $\mathrm{Ca}^{2+}$ signaling is a dynamic process used by cells to decode extracellular signals and respond to energy requirements or to adapt to stress in a spatiotemporal fashion. This precise process relies on different protein entities, some of which are unknown, depending on the organelles involved.

Under resting conditions, the cytosolic $\mathrm{Ca}^{2+}$ concentration $\left(\left[\mathrm{Ca}^{2+}\right]_{\mathrm{cyt}}\right)$ is maintained at approximately $100 \mathrm{nM}$; some organelles, such as the endoplasmic reticulum (ER) and Golgi apparatus, act as intracellular $\mathrm{Ca}^{2+}$ stores, accumulating cation concentrations on the order of hundreds of $\mu \mathrm{M}$ [2]. The extensive membranous network of the ER includes multiple sites in close proximity to the plasma membrane (PM) to facilitate luminal $\mathrm{Ca}^{2+}$ refilling through store-operated $\mathrm{Ca}^{2+}$ entry (SOCE) channels and the sarco/endoplasmic reticulum $\mathrm{Ca}^{2+}$ ATPase (SERCA) pumps $[3,4]$. This process is regulated at the ER-PM platform by stromal interaction molecule 1 (STIM1), an ER transmembrane protein that senses the intraluminal $\mathrm{Ca}^{2+}$ level and recruits the $\mathrm{PM} \mathrm{Ca}{ }^{2+}$ channel protein ORAI1, leading to $\mathrm{Ca}^{2+}$ refilling in the ER [5] (Fig. 1). Additionally, $\mathrm{Ca}^{2+}$ signaling to endolysosomes may be generated by juxtaposition with the ER (Fig. 1). An intimate relationship exists between the ER and endosomal system to initiate $\mathrm{Ca}^{2+}$ signaling or to store and buffer the released $\mathrm{Ca}^{2+}$. Endolysosomes are connected to other organelles, such as mitochondria, the PM and the Golgi apparatus. At these contact sites, not only $\mathrm{Ca}^{2+}$ is exchanged but also lipids (particularly cholesterol) and free radicals are transferred

* Corresponding authors at: Dept. of Morphology, Surgery and Experimental Medicine, Section of Pathology, Oncology and Experimental Biology, Via Fossato di Mortara, 70, 44121 Ferrara, Italy.

E-mail addresses: alessandro.rimessi@unife.it (A. Rimessi), paolo.pinton@unife.it (P. Pinton).

${ }^{1}$ These authors contributed equally to this work. 


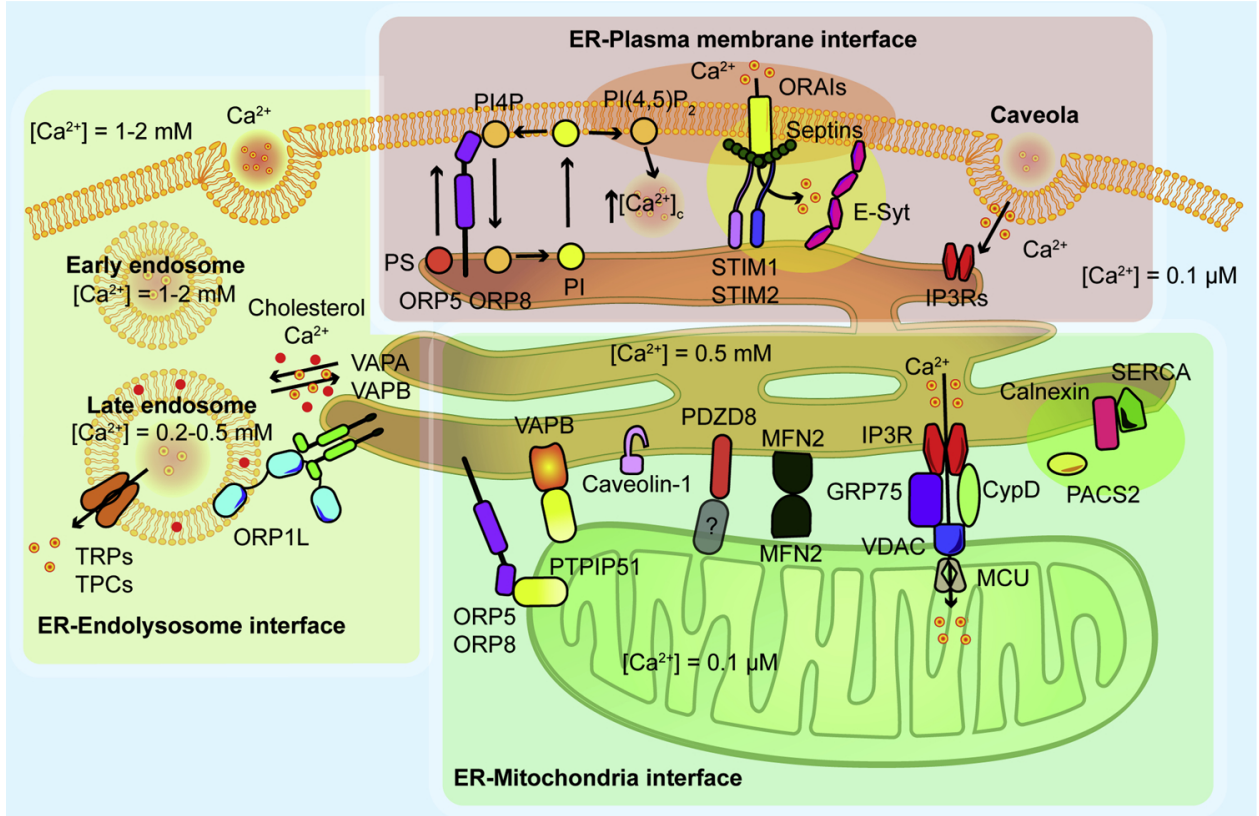

Fig. 1. Description of $\mathrm{Ca}^{2+}$ transfer between different organelles by different $\mathrm{Ca}^{2+}$ effectors and their interactors in the modulation of interorganelle tethering. The circled groups of proteins have mutual regulatory activity. CypD, cyclophilin D; E-Syt, extended-synaptotagmin; GRP75, mortalin; IP3R, inositol 1,4,5trisphosphate receptor; $\mathrm{MCU}$, mitochondrial $\mathrm{Ca}^{2+}$ uniporter; MFN2, mitofusin 2; ORAIs, $\mathrm{Ca}^{2+}$ release-activated $\mathrm{Ca}^{2+}$ channel proteins; ORP, oxysterol-binding protein; PACS-2, phosphofurin acidic cluster sorting protein 2; PDZD8, PDZ domain-containing protein 8; PI4P, phosphatidylinositol 4-phosphate; PS, phosphatidylserine; PI, phosphatidylinositol; PI(4,5)P2, phosphatidylinositol 4,5-bisphosphate; PTPIP51, phosphatase-interacting protein 51; SERCA, sarco/endoplasmatic reticulum $\mathrm{Ca}^{2+}$ ATPase; STIM1, stromal interaction molecule 1; STIM2, stromal interaction molecule 2; TPCs, two-pore channels; TRPs, transient receptor potential channels; VAPA, vesicle-associated membrane proteinassociated protein A; VAPB, vesicle-associated membrane protein-associated protein B; VDAC, voltage-dependent anion channel. between the organelles as messengers.

Adequate $\mathrm{Ca}^{2+}$ transfer between cellular compartments requires a proper tether; for the PM, transfer is supported by caveolar lipid rafts, which are cellular invaginations $50-100 \mathrm{~nm}$ deep that form a spatial link between two membranes to facilitate interactions between these two structures [4]. The importance of caveolae in $\mathrm{Ca}^{2+}$ signaling is confirmed by the strategic localization of pivotal $\mathrm{Ca}^{2+}$ effectors, such as SOCE channels, PM Ca ${ }^{2+}$ ATPase pumps and inositol 1,4,5-trisphosphate (IP ${ }_{3}$ ) receptor (IP3R)-like proteins, and by the existence of specific $\mathrm{Ca}^{2+}$ microdomains in the lumina of caveolae, which provide a platform for the assembly of diverse $\mathrm{Ca}^{2+}$ signaling complexes [6-9]. Transient increases in the $\left[\mathrm{Ca}^{2+}\right]_{\text {cyt }}$ occur through $\mathrm{Ca}^{2+}$ release from the ER via IP3Rs or ryanodine receptors and by the entry of $\mathrm{Ca}^{2+}$ from the extracellular space. The ER-mitochondria interface is a specialized membrane domain called the mitochondrial-associated membrane (MAM) and is the location of $\mathrm{Ca}^{2+}$ transfer from the ER to mitochondria [10] (Fig. 1). Ions released by IP3Rs cross the outer mitochondrial membrane (OMM) via the voltage-dependent anion channel (VDAC) to enter the mitochondrial matrix through the mitochondrial $\mathrm{Ca}^{2+}$ uniporter (MCU) complex. This selective $\mathrm{Ca}^{2+}$ channel in the inner mitochondrial membrane (IMM) and the mitochondrial membrane potential $\left(\Delta \Psi_{\mathrm{m}}\right)$, the driving force for $\mathrm{Ca}^{2+}$ accumulation, play a fundamental role in shaping mitochondrial $\mathrm{Ca}^{2+}$ signaling and in controlling aerobic metabolism as well as cell death [11,12].

In this review, we focus on interorganelle platforms that operate $\mathrm{Ca}^{2+}$ transfer involving the ER. We review the mechanisms by which these platforms control the interorganellar $\mathrm{Ca}^{2+}$ distribution to regulate cell metabolism and the ways in which they are linked to the development of tumors.

\section{Structural and functional features of interorganellar coupling}

Advances in imaging technologies and/or isolate membrane contact sites in living cells have permitted partial identification of the molecular identity and activities of proteins residing within these intimate regions. In addition to the molecular determinants, pivotal structural features such as the frequency of organelle contact, the spacing between both organelles and the size of the contact region must be considered. These parameters, which differ among cells, are extremely variable and strictly dependent on the functional context.

The ER is the most interconnected cellular organelle, and mediating its resident proteins may allow them to contact their partners on other organelles to generate interorganellar coupling, through which $\mathrm{Ca}^{2+}$ can be exchanged. These interconnections are discussed individually in this section, and the principal features are highlighted.

\subsection{ER-mitochondria interface}

The first evidence of an interaction between the ER and mitochondria was obtained using electron microscopy in 1959, but this interaction was long considered an artifact [13]. The ER-mitochondria interface was isolated in 1990, and further experimental approaches have confirmed the physical proximity and functionality of ER-mitochondrial coupling [14-16].

The distance between these two membranes is 10-30 nm [17], and only approximately $10 \%$ of the mitochondrial surface is in direct contact with the ER [15]. The transfer of $\mathrm{Ca}^{2+}$ from the ER to mitochondria is optimal at a distance of $15 \mathrm{~nm}$ [18], although MAMs are dynamic structures, and the distance and the amount of mitochondria involved varies between cellular and functional contexts. Whether all ER-mitochondrial coupling connections have the same protein composition is unclear, but high-resolution electron tomography has shown the presence of physical linkers [19], and the protein interactions between ER and mitochondria can result in a tethering complex. To date, three proteomics studies have been performed to analyze the protein composition of MAM fraction [20-22]. Initially, in NG108/105 cells, the authors identified 250 proteins in MAMs but 991 proteins were modulated in MAMs in human fibroblasts after infection. In addition, Sala-Vila et al. reported that caveolin-1 (cav1), which enhances $\mathrm{Ca}^{2+}$ uptake into mitochondria to promote its tumor suppressor activity, is an important component of this domain [23]. These studies suggest that several proteins are involved in the formation and/or stabilization of ER-mitochondrial coupling; furthermore, modulating the expression of specific proteins in MAMs seems to be sufficient to destabilize this interaction.

The molecular identity of ER-mitochondrial tethering is well defined in yeast; an elegant genetic screen identified the ER-mitochondria encounter structure (ERMES) and, subsequently, the ER membrane complex (EMC) [24]. The ERMES complex tethers ER to mitochondria, forming approximately two to ten foci per yeast cell, while the EMC complex interacts with the mitochondrial protein Tom5, forming a tether between the two organelles [25]. 
The molecular identity of ER-mitochondrial tethering in mammalian cells is less clear. In mammalian cells, ERMES homologs have not been identified, but several proteins have been demonstrated to modulate the ER-mitochondria platform. Although all of these proteins may not abolish ER-mitochondrial coupling, only the identified PDZD8 seems necessary for the formation of ER-mitochondrial contacts in mammalian cells [26]. PDZD8 is an ER protein required for mitochondrial $\mathrm{Ca}^{2+}$ uptake in neurons; if PDZD8 is deleted, the average surface area of individual ER-mitochondria contacts decreases by approximately $80 \%$. Indeed, PDZD8 contains an SMP domain that is functionally orthologous to the SMP domain (synaptotagmin-like mitochondrial-lipid binding protein domain) found in the ERMES component $\mathrm{Mmm} 1$. However, the respective mitochondrial partner of PDZD8 involved in ER-mitochondrial coupling is unidentified.

Another example of a protein regulating ER-mitochondrial coupling is the phosphofurin acidic cluster sorting 2 (PACS-2) protein. PACS-2 deletion causes mitochondrial fragmentation and reduced apposition to the ER, leading to the inhibition of interorganelle $\mathrm{Ca}^{2+}$ signal transmission [27], while PACS-2 overexpression enhances ER-mitochondrial interactions and $\mathrm{Ca}^{2+}$ exchange [28]. The precise role of PACS-2 in ERmitochondrial coupling has not been completely elucidated; however, it plays a pivotal role in the trafficking of ion channels between secretory pathway compartments [29] and regulates the activity of calnexin, an ER chaperone enriched in MAMs that can modulate intraluminal $\mathrm{Ca}^{2+}$ signaling through SERCA activity [30].

The role of mitofusin 2 (MFN2) as an ER-mitochondria tether is debatable. This mitochondrial protein, which controls organelle fusion, is localized at both the OMM and at ER and forms tethers between the ER and mitochondria, thus influencing $\mathrm{Ca}^{2+}$ transfer [31]. Disruption of ER-mitochondrial interactions and $\mathrm{Ca}^{2+}$ transfer in $\mathrm{Mfn} 2-/-$ mouse embryonic fibroblasts indicated that the distance between these two organelles increases when this protein is deleted [31]. Recently, this concept was debated because new experiments performed in the same Mfn2 knockout cells showed increased ER-mitochondrial interactions and $\mathrm{Ca}^{2+}$ transfer, suggesting that further investigations are necessary to pinpoint the exact role of MFN2 [32,33].

Another well-known protein complex, which is strongly correlated with functional ER-mitochondria apposition, is the $\mathrm{Ca}^{2+}$ channeling complex formed by IP3R at the ER and the chaperone glucose-regulated protein 75 (GRP75) and VDAC at the OMM [34]. This complex has also been associated with cyclophilin D, enriched in the MAM fraction, as this new partner of the complex can regulate interorganellar $\mathrm{Ca}^{2+}$ flux in hepatocytes and cardiomyocytes [35-37]. However, this complex does not seem to have features of a physical tether; in DT40 cells, knocked out for all the isoforms of IP3R3, the ER-mitochondria contacts are unmodified [17].

Finally, both the ER-resident vesicle-associated membrane proteinassociated protein $\mathrm{B}$ (VAPB) and the mitochondrial tyrosine phosphatase-interacting protein 51 (PTPIP51) are involved in physical and functional ER-mitochondrial coupling [38]. Genetic manipulation of these mediators induces alterations in ER-mitochondrial coupling and interorganellar $\mathrm{Ca}^{2+}$ transfer, with repercussions on autophagy $[39,40]$. In addition, VAPB participates in ER-Golgi coupling where the ER is located very close (approximately $10 \mathrm{~nm}$ ) to the trans-Golgi network [41] through interaction with ceramide transport protein (CERT), which is relevant to ceramide transport via ER-Golgi contact sites [42]. Indeed, interaction between mitochondrial PTPIP51 and the ER-resident oxysterol-binding protein (OSBP)-related proteins ORP5 and ORP8 at MAMs has recently been demonstrated; these proteins are involved in the ER-PM interface and in phosphatidylserine (PS) transfer, suggesting an interconnection among these three structures $[43,44]$.

\subsection{ER-plasma membrane interface}

ER-PM coupling, described for the first time in 1957 in muscle, is a ubiquitous structural feature in all mammalian cells [45]. These membrane contact sites are involved in numerous functions, such as $\mathrm{Ca}^{2+}$ homeostasis regulation, lipid exchange, non-vesicular cholesterol transport and organelle dynamics [46]. Such specialized ER domains, preferentially associated with PM, are called the PM-associated membranes (PAM) fraction, containing many types of intracellular membranes (mainly ER but also mitochondria) that can be co-isolated with the PM. These membranes are not fused, the distance between the ER and PM is approximately $10-30 \mathrm{~nm}$; this distance is regulated by the presence of molecular tethers [47-49]. Although ER-PM coupling has been previously observed, the molecular identity of this connection remains largely elusive. However, in 2012, Toulmay et al. identified the ER tricalbins as ER-PM tethering molecules in yeast [50]. The mammalian homologs of tricalbins are the three isoforms of extended synaptotagmins (E-Syt), ER proteins implicated in ER-PM coupling, lipid transfer and $\mathrm{Ca}^{2+}$ signaling [51]. The lipid composition of the PM is very important for intracellular signaling and is regulated by the local $\left[\mathrm{Ca}^{2+}\right]_{\mathrm{cyt}}$ at the ER-PM interface. ORP5 and ORP8, found at the ER-PM interface, are implicated in this process via transferring PS from the ER to the PM, which drives the countertransport of phosphatidylinositol 4phosphate to the ER. At the ER membrane, phosphatidylinositol 4phosphate is converted to phosphatidylinositol (PI), which is transported back to the PM and rapidly converted to phosphatidylinositol 4phosphate and phosphatidylinositol 4,5-bisphosphate (PIP2), which mediating PLC is metabolized to diacylglycerol (DAG) and IP3. In turn, IP3 production leads to an increase in the cytoplasmic $\mathrm{Ca}^{2+}$ concentration via IP3Rs and SOCE response [12,52]. STIM1 and STIM2 in the ER and the three isoforms of the ORAI channel at the PM are the key determinants orchestrating the SOCE response at the ER-PM interface [53]. Under resting conditions, dimers of STIM proteins and hexamers of ORAI subunits are freely diffused along all ER and PM membranes. Intraluminal $\mathrm{Ca}^{2+}$ depletion from the store regulates the loss of $\mathrm{Ca}^{2+}$ ions from the luminal EF-hand motifs on STIM, which induces a conformational change in the structure favoring STIM oligomerization and translocation to the ER-PM interface. This clustering of STIM at the ERPM interface blocks the free diffusion of ORAI hexamers, thus favoring ORAI oligomerization, which results in $\mathrm{Ca}^{2+}$ influx at the ER-PM interface [54]. The SOCE response is completed through the deoligomerization of the STIM-ORAI complex when the intraluminal $\mathrm{Ca}^{2+}$ level in the ER has been replenished. Caveolae are the preferred interorganelle platform for SOCE, and this domain can simultaneously release $\mathrm{Ca}^{2+}$ in an IP3R-dependent manner [55].

The depletion of E-Syt alters the $\mathrm{Ca}^{2+}$-dependent activation of ORAI channels, indicating crosstalk between E-Syt in ER-PM tethering and STIM-ORAI signaling [56]. Indeed, ER $\mathrm{Ca}^{2+}$ store depletion induces rapid septin rearrangement and PIP2 redistribution at the ER-PM interface to favor a functional STIM-ORAI interaction [57]. These rearrangements are necessary for efficient STIM-ORAI interactions and SOCE channel gating. Septins are scaffold proteins redistributed at the PM; their participation in the formation of ORAI clusters control PIP2 redistribution in the lipid microdomain, which is necessary for STIMORAI complex stability [57]. These observations confirm that efficient ER-PM $\mathrm{Ca}^{2+}$ transfer occurs through the dynamic redistribution not only of proteins but also lipids to the ER-PM interface.

\subsection{ER-endolysosome interface}

An additional intimate coupling relationship of the ER is represented by its interaction with the endosomal system. This process is controlled by cholesterol levels in the endosome and occurs through the interaction of the endosomal cholesterol-sensing protein oxysterolbinding protein-related protein $1 \mathrm{~L}$ (ORP1 L) with the ER proteins VAPA and VAPB [58]. Coupling between these organelles favors the participation of the ER in endosomal processes such as transport and fusion events, vesicular body formation and receptor management. At these contact sites, messengers such as lipids and $\mathrm{Ca}^{2+}$ are exchanged between the coupled organelles. 
Endosomes not only release extracellular $\mathrm{Ca}^{2+}$ to induce new intracellular $\mathrm{Ca}^{2+}$ signaling cascades but also store and buffer $\mathrm{Ca}^{2+}$ released from the ER upon stimulation. Early endosomes, which are derived from membrane endocytosis, may engulf extracellular $\mathrm{Ca}^{2+}$ at concentrations similar to those in the extracellular environment, on the order of 1-2 mM [59]. This internalized $\mathrm{Ca}^{2+}$ is released from endosomes through transient receptor potential (TRP) channels and twopore channels [60-63], reducing the luminal $\mathrm{Ca}^{2+}$ concentration to approximately $3-40 \mu \mathrm{M}[64,65]$. $\mathrm{Ca}^{2+}$ release from endosomes may also induce $\mathrm{ER} \mathrm{Ca}^{2+}$ mobilization and vice versa, indicating that the ER-endolysosome interface is a dynamic site for $\mathrm{Ca}^{2+}$ crosstalk between these organelles.

Late endosomes and lysosomes exhibit $\mathrm{Ca}^{2+}$ concentrations similar to ER (approximately $0.2-0.5 \mathrm{mM}$ ), suggesting that mature endosomes can absorb $\mathrm{Ca}^{2+}$ through unknown $\mathrm{Ca}^{2+}$ uptake channels [66,67] and, like the ER, store the ion [68-70]. The fact that endolysosomal $\mathrm{Ca}^{2+}$ concentrations are much higher than the $\left[\mathrm{Ca}^{2+}\right]_{\mathrm{cyt}}$ suggests that endolysosomal compartments actively participate in the induction of intracellular $\mathrm{Ca}^{2+}$ signaling, in turn suggesting that endolysosomes might generate a $\mathrm{Ca}^{2+}$ flux similar to that between the ER and mitochondria or the ER and the PM.

\section{Interorganelle crosstalk in energy metabolism}

Although organelles are functional units compartmentalized to perform specific metabolic tasks, they are interconnected by a system of $\mathrm{Ca}^{2+}$ communication to adapt to environmental changes.

\subsection{ER-mitochondria interface}

The ER participates in several anabolic and catabolic processes, such as protein synthesis and degradation, gluconeogenesis, glycogen synthesis and breakdown, membrane lipid synthesis and recycling [71]. The synthesis of most membrane phospholipids occurs on the ER membrane, and the products are subsequently sent through the interorganelle platform to other organelles by mechanisms that are partially unknown.

MAMs play an important role in lipid metabolism; in fact, these domains contain different enzymes linked to the biosynthesis and transfer of phospholipids, triacylglycerols, cholesterol, and cholesteryl esters [72]. The role of lipids at MAMs in the physical interaction between the ER and mitochondria has been thoroughly investigated, showing the impact of cholesterol and raft-like microdomains. In particular, cholesterol is an important substrate in regulating the association between the ER and mitochondria [73]. Increased ceramide level, an important mitochondrial sphingolipid, is associated with the initiation of apoptosis by OMM permeabilization. Interestingly, ceramide synthesis, occurs in the ER and partially in mitochondria and at the MAMs [74].

The ER hosts several enzymes involved in protein and lipid metabolism, and perturbations in the homeostasis of cellular energy production, redox state or $\mathrm{Ca}^{2+}$ concentration leads to ER stress and the activation of unfolded protein response (UPR) signaling. The UPR maintains protein homeostasis, but numerous later studies suggest that the UPR can also control lipid homeostasis. ER stress and proteins involved in UPR signaling have been found to control hepatic lipid metabolism, thus participating in hepatic steatosis and insulin resistance $[75,76]$. Furthermore, ER stress has been reported to induce autophagy and to exert a general effect on glucose metabolism [77]. Autophagy is a conserved and tightly regulated catabolic process that regulates metabolic homeostasis, permitting the degradation of organelles or cytoplasmic constituents to obtain energy [78]. Moreover, in 2013, Hamasaki et al. demonstrated that ER-mitochondria contact sites are important in autophagosome formation [79].

During the adaptive phases of ER stress, both the reticular and mitochondrial network redistribute towards the perinuclear area, augmenting the coupling of these organelles and the contact sites to potentiate interorganellar $\mathrm{Ca}^{2+}$ transfer to initiate metabolic adaptation that increases mitochondrial bioenergetics [80].

In mitochondria, $\mathrm{Ca}^{2+}$ is a fundamental metabolic messenger essential to the control of mitochondrial metabolic activity in support of oxidative phosphorylation (OXPHOS): specifically, $\mathrm{Ca}^{2+}$ regulates the activity of pyruvate, NAD-isocitrate dehydrogenase and oxoglutarate dehydrogenase and the consequent production of ATP by the respiratory chain [81,82]. Recently, an alteration in mitochondrial bioenergetics has been found in cancer cell metabolism; this alteration is linked to mutations in enzymes of the TCA cycle, including succinate dehydrogenase, fumarate hydratase and isocitrate dehydrogenase $[83,84]$ and arises due to metabolic reprogramming that is required to support uncontrolled growth and proliferation in the tumor environment. In particular, the loss of function of fumarate hydratase has been linked to a subset of cancers in which cells are respiratory-deficient and accumulate high levels of fumarate with a general impairment of energy metabolism [85].

The role of $\mathrm{Ca}^{2+}$ in cardiac mitochondria isolated from pigs has been studied; $\mathrm{Ca}^{2+}$ was demonstrated to activate cardiac aerobic respiration at the level of both the $\mathrm{Ca}^{2+}$-sensitive dehydrogenases and the $\mathrm{F}_{\mathrm{o}} \mathrm{F}_{1}$ ATPases [86]. These observations have also been reported in isolated skeletal muscle mitochondria, where $\mathrm{Ca}^{2+}$ increases the conductance of complexes I, III and IV and the consequent ATP production [87]. Mitochondria control metabolic flexibility because their biogenesis and function are adapted to conditions of nutrient limitation or caloric excess to restore energy homeostasis, which is why some metabolic pathologies, such as type 2 diabetes mellitus and obesity, are also linked to mitochondrial dysfunction [88].

Indeed, in the ER, one role of $\mathrm{Ca}^{2+}$ is to control the calreticulin/ calnexin cycle, which is responsible for overseeing the folding of newly synthesized proteins. In particular, studies in calreticulin knockout mice have highlighted a role of this protein in controlling cellular differentiation and organ development via a $\mathrm{Ca}^{2+}$-dependent mechanism [89]. In 2019, Brandt et al. found a novel involvement of calnexin in triacylglycerol synthesis, showing that calnexin interacts with acyl CoAdiacylglycerol acyltransferase-2 (DGAT2), an integral membrane protein of the ER and that calnexin-deficient mouse embryonic fibroblasts exhibited lower intracellular triacylglycerol levels and produced smaller lipid droplets than their wild-type counterparts [90].

In the last year, different studies have correlated the spatial organization of IP3Rs in clusters in the ER membrane with the propagation of $\mathrm{Ca}^{2+}$ signals in the regulation of cellular homeostasis. All three IP3R isoforms cluster to generate local $\mathrm{Ca}^{2+}$ puffs with largely similar mean amplitudes, temporal characteristics, and spatial extents in intact cells [91]; most of these clusters move via linkage to microtubules, but a small subset are immobile and involved in $\mathrm{Ca}^{2+}$ signaling. These IP3Rs have an optimal localization: near ER-PM junctions where STIM1 accumulates after $\mathrm{Ca}^{2+}$ store depletion [92].

IP3Rs modulate several $\mathrm{Ca}^{2+}$-mediated processes and participate in cellular metabolism; in particular, studies in IP3R knockout cells have revealed significant perturbations in the energy charge and reduced glutathione and NADPH ratios, along with a decreased cellular growth rate, linked to higher reactive oxygen species (ROS) levels [93]. The absence of basal constitutive low-level $\mathrm{Ca}^{2+}$ signaling by IP3Rs has been demonstrated to lead to metabolic impairment resulting from diminished $\mathrm{Ca}^{2+}$ uptake by mitochondria: this condition enhances the phosphorylation and inhibition of pyruvate dehydrogenase and the activation of AMPK, which in turn activates prosurvival autophagy by a mTOR-independent mechanism [82].

In addition, downregulation of IP3R1 has been demonstrated to result in improved mitochondrial respiration, decreased cellular stress and enhanced glucose tolerance in obese animals [28], suggesting an important role of this receptor in mitochondrial metabolism.

Metabolic homeostasis is dependent on both the energy and redox statuses. Mitochondria producing ATP for the cellular energy supply are 
also the primary source of intracellular ROS generation due to electron leakage from the respiratory chain. Complex I and complex III are the main sources of ROS production, although complex II also contributes [94]. Excessive ROS can lead to cell death by oxidative stress; however, recent studies reveal a new role of mitochondrial ROS as signaling molecules: these molecules act to improve metabolic homeostasis and signal transduction [95,96]. Diverse enzymes involved in ER redox homeostasis are located at MAMs: for example, glutathione peroxidase 8 (GPX8) is enriched in ER-mitochondria interface to regulate ER $\mathrm{Ca}^{2+}$ storage and fluxes [97]. Localization of Ero1 $\alpha$ at MAMs depends on oxidizing conditions within the ER; this localization requires normoxic conditions and is linked to the role of Ero1< in the regulation of ER $\mathrm{Ca}^{2+}$ release by IP3Rs during ER stress [98,99]. In addition, GRP75 plays a role in mitochondrial functionality and redox homeostasis in neuronal cells: GRP75 silencing counteracts both cytosolic and mitochondrial $\mathrm{Ca}^{2+}$ overload under conditions of oxidative stress, blocking the production of ROS and preserving mitochondrial respiration through the maintenance of ER-mitochondrial coupling [100].

VDAC1 plays an important role in the energy metabolism of mitochondria because it controls the electron transport chain and metabolite exchange across mitochondrial membranes [101]; in fact, downregulation of VDAC1 expression decreases metabolite flux between mitochondria and the cytosol and inhibits cell growth [102].

Furthermore, MCU mediates mitochondrial $\mathrm{Ca}^{2+}$ uptake in pancreatic $\beta$-cells, and this $\mathrm{Ca}^{2+}$ accumulation is fundamental for the sensing of normal glucose levels [103]. In fact, a relationship between changes in the $\mathrm{Ca}^{2+}$ concentration in the mitochondrial matrix and consequent increases in the cytosolic ATP/ADP ratio that induces glucose-stimulated insulin secretion [104] has been demonstrated.

In the liver, altered insulin signaling is often associated with impaired mitochondria or ER stress; in fact, disruption of MAM integrity leads to altered insulin signaling in both mouse and human primary hepatocytes and in vivo [36]. These data demonstrate that MAM integrity controls hepatic insulin action and resistance. Similar alterations in insulin signaling have been found in cardiac hypertrophy, where insulin stimulates $\mathrm{Ca}^{2+}$ release from the ER and increases mitochondrial $\mathrm{Ca}^{2+}$ levels [105]. Arruda et al. showed that in the liver of obese mice, there is a profound reorganization of MAMs that establishes excessive ER-mitochondrial coupling, resulting in mitochondrial $\mathrm{Ca}^{2+}$ overload, impaired metabolic homeostasis, compromised mitochondrial oxidative capacity and augmented oxidative stress that can be correlated with the progression of insulin resistance and diabetes [28].

The expression of PTPIP51, which, in adipose tissue, acts as an effector in insulin signaling, has been correlated with insulin resistance [106]. Recent evidence has identified a role for this protein in adipocyte metabolism as a mediator between lipogenesis and lipolysis by switching between the lipogenic insulin pathway and the lipolytic PKA pathway via physical interaction with the insulin receptor and PKA [107]. VAPB-PTPIP51 tethers regulate autophagy by controlling $\mathrm{Ca}^{2+}$ influx to mitochondria from the ER [40]. In C. elegans, loss of the ERresident VAP homolog VPR-1 causes triacylglycerol accumulation in muscular compartments; similar data have been obtained in VAPB knockout mice, indicating the presence of mitochondrial dysfunction that affects energy metabolism [108]. Mutations in VAPB/ALS8 are also associated with amyotrophic lateral sclerosis and spinal muscular atrophy [109,110].

An important signaling protein at the ER-mitochondria interface is mammalian target of rapamycin complex 2 (mTORC2): its localization to MAMs is stimulated by growth factors and insulin, and its interaction with the IP3R-Grp75-VDAC1 complex via Akt leads to the phosphorylation of the MAM-associated proteins IP3R, hexokinase 2 and PACS-2, with an effect on growth and metabolism [111]. In addition, Akt is involved in mediating insulin resistance; the phosphatidylinositol-3 kinase $\left(\mathrm{PI}_{3} \mathrm{~K}\right)$-Akt pathway is an important effector of insulin induction and induces the translocation of glucose transporters (GLUTs) to the cell membrane in order to increase glucose uptake [112].
Another tether protein, PACS-2, has been demonstrated to be involved in lipid metabolism. In fact, this MAM-regulating protein mediates the levels of the MAM-associated FACL4 protein, which converts fatty acids to the fatty acyl-CoA esters used in the formation of complex lipids, and PSS-1, which exchanges the head group of phosphatidylcholine with serine [27]. Recent evidence shows that PACS-2 mediates metabolism, interfering with SIRT1-dependent PGC-1 $\alpha$ deacetylation. PACS-2 knockout mice were protected from diet-induced insulin resistance and obesity [28]. Additionally, MFN2 deficiency has been linked to impaired insulin signaling and glucose homeostasis in vivo, which is associated with ER stress and altered ROS handling [113]. MFN2 depletion modifies the cellular metabolic profile in different cell models, leading to reduced $\Delta \Psi_{\mathrm{m}}$; cellular oxygen consumption; and decreased oxidation of glucose, pyruvate, and fatty acids [114-117]. In particular, MFN2 depletion represses the expression of nuclear encoded subunits of OXPHOS complexes I (p39), II (p70), III (p49), and V ( $\alpha$ subunit), leading to decreased metabolic activity [115,118]. However, the way in which MFN2 can alter OXPHOS subunit expression is unclear.

\subsection{ER-plasma membrane interface}

The most thoroughly documented functions of the ER-PM platform are maintaining intracellular $\mathrm{Ca}^{2+}$ homeostasis and mediating lipid metabolism [119].

ER-PM platforms are hubs for lipid metabolism and the transport of phospholipids and sterols; these domains have a high capacity for PI and PS synthesis [120]. At the ER-PM interface, the SMP domain-containing ER membrane protein TMEM24 contributes to insulin secretion in brain, neuronal and insulinoma cells [121].

By contributing to intracellular $\mathrm{Ca}^{2+}$ signaling, ER-PM platforms support the regulation of cytosolic $\mathrm{Ca}^{2+}$ signaling involved in several metabolic processes. In the liver, for example, oscillations in the $\left[\mathrm{Ca}^{2+}\right]_{\mathrm{cyt}}$ act as signals for circulating hormones to regulate glycogenolysis, gluconeogenesis and mitochondrial metabolism; therefore, $\mathrm{Ca}^{2+}$ dysregulation leads to pathologies such as metabolic syndrome and nonalcoholic fatty liver disease [122].

ORP5 and ORP8 localize to both ER-PM and ER-mitochondria appositions to facilitate organelle interaction and to transport PIP2 in order to modulate mitochondrial morphology and respiration [123]. In fact, overexpression of ORP5/8 favored mitochondrial function, augmenting cell proliferation through increasing the $\mathrm{Ca}^{2+}$ concentration in caveolae on the PM and mitochondrial matrix [124].

Cav1, a fundamental constituent of caveolae, is the core component of the $\mathrm{Ca}^{2+}$-dependent apoptotic pathway and participates in the regulation of critical mitochondrial functions during tumor development: impairment of the cav1/ $\mathrm{Ca}^{2+}$ axis leads to mitochondrial metabolic failure and apoptosis [23].

E-Syt are directly implicated in the mobilization of ER-PM platforms for autophagosome biogenesis. Autophagy is enhanced in cells overexpressing E-Syt, while inhibition of E-Syt significantly reduced autophagosome biogenesis [125]. Specifically, Nascimbeni et al. demonstrated that VMP1 interacts with E-Syt and that stress-induced mobilization of Beclin1 leads to the formation of a Beclin1-VMP1-E-Syt complex at ER-PM junctions to ensure the spatiotemporal regulation of phosphatidylinositol 3-phosphate synthesis required for autophagosome biogenesis.

\subsection{ER-endolysosome interface}

Lysosomes are involved in both catabolic and metabolic processes and control cell functionality. The core machinery that oversees the fusion of the endosome and autophagosome with the lysosome represents the terminal degradative compartment of the cellular endocytic and autophagic pathways. In addition to this fundamental role, lysosomes mediate various cellular mechanisms (reviewed in [126]), 
one of which is $\mathrm{Ca}^{2+}$ storage and, therefore, $\mathrm{Ca}^{2+}$ signaling. In fact, because of the different $\mathrm{Ca}^{2+}$ channels present on their membrane, lysosomes can both store and release $\mathrm{Ca}^{2+}$, directly communicating with the ER [61].

Lysosomal $\mathrm{Ca}^{2+}$ signaling, mainly involved in fusion/fission events, is strongly amplified by the subsequent stimulation of $\mathrm{ER} \mathrm{Ca}^{2+}$ release, connecting lysosomes to different cellular processes (reviewed in [127]). Mucolipin 1 (MCOLN1)-mediated endolysosomal $\mathrm{Ca}^{2+}$ release results in calcineurin activation, which in turn dephosphorylates TFEB and up-regulates genes involved in lysosomal biogenesis via the expression of coordinated lysosomal expression and regulation (CLEAR) elements [128]. The ER is the primary source of $\mathrm{Ca}^{2+}$ for the lysosome [129], in agreement with the close physical proximity and formation of contact sites between these organelles. ER-lysosome platforms were first observed in mammalian cells, revealing the mechanism behind the interaction of PTP1B, an ER-localized protein phosphatase, and the endosomal EGF receptor [130]. In the endolysosomal system, $\mathrm{Ca}^{2+}$ is released through two-pore channels that can be activated by the pyridine nucleotide metabolite NAADP, an important intracellular second messenger in mammalian cells [131,132]. Interestingly, two-pore channel-mediated $\mathrm{Ca}^{2+}$ release is influenced by lysosomal $\mathrm{pH}$, and vice versa [133]. An example of the precise crosstalk between the ER and lysosomes occurs in cardiac myocytes, where NAADP induces the formation of microdomains with high $\mathrm{Ca}^{2+}$ concentrations between lysosomes and the sarcoplasmic reticulum in response to $\beta$-adrenoceptor activation [134].

\section{Dysregulation of interorganellar communication in cancer}

$\mathrm{Ca}^{2+}$ communication between organelles, either indirectly or directly through membrane contact, is fundamental for proper cell function and for the maintenance of tissue homeostasis. Disruption of this extensive $\mathrm{Ca}^{2+}$ signaling network is detrimental for the entire organism, leading to the development of pathological conditions, including cancer. $\mathrm{Ca}^{2+}$ impairment is frequently associated with the dysregulation of several $\mathrm{Ca}^{2+}$ channels and pumps [135,136]. Alterations in cellular physiology acquired by cancer cells include cell sufficiency in growth signals, insensitivity to growth inhibitory cues and the ability to evade programmed cell death; in turn, these processes are affected by communication between organelles [137]. Moreover, many oncogenic pathways supporting tumor cell growth and survival converge on cellular metabolism, which mainly relies on energy production and thus mitochondrial function [138].

\subsection{ER-mitochondria interface}

ER and mitochondria use $\mathrm{Ca}^{2+}$ to communicate in response to physiological and pathological stimuli. The main biological processes involving contact between the ER and mitochondria are the control of lipid biosynthesis, $\mathrm{Ca}^{2+}$ transfer, mitochondrial division and biogenesis [139]. These fine-tuned ER-mitochondrial dynamics control several aspects of cell survival, such as metabolism and sensitivity to cell death. Impaired $\mathrm{Ca}^{2+}$ handling can prevent mitochondrial $\mathrm{Ca}^{2+}$ overload and the dissociation of $\mathrm{F}_{\mathrm{o}} \mathrm{F}_{1} \mathrm{ATP}$ synthase dimers at the base of permeability transition pore (PTP) openings [140], sustaining tumorigenesis through apoptosis evasion.

During the past decades, an increasing number of oncogenes and tumor suppressor genes have been shown to exert a function at the ERmitochondria interface through the regulation of $\mathrm{Ca}^{2+}$ signaling (Fig. 2) [141].

$\mathrm{Bcl}-2$, the primary member of the Bcl-2 family, is a protooncogene known for its roles in inhibiting apoptosis (via interaction with the proapoptotic proteins Bax and Bak) and in promoting oncogenesis. Bcl2 localizes in the ER and on the OMM [142] and directly inhibits the function of IP3Rs via the interaction of its N-terminal BH4 domain with the three isoforms of the channel [143]. These complex interactions

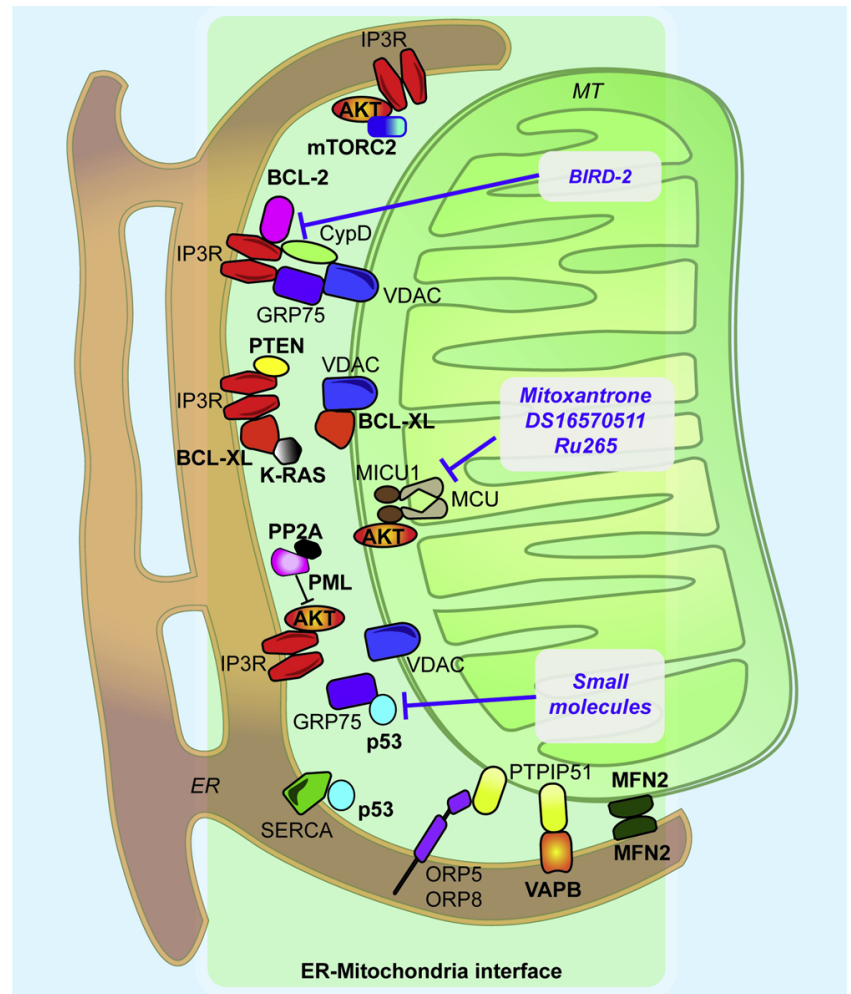

Fig. 2. Main ER-mitochondria $\mathrm{Ca}^{2+}$ transfer pathways dysregulated in tumorigenesis. Proteins up- or downregulated in cancer are shown in bold font. Drugs or compounds acting on $\mathrm{Ca}^{2+}$ at the ER-mitochondria interface are indicated in the squares. Akt, protein kinase B; Bcl-2, B-cell CLL/lymphoma 2; Bcl-xL, B-cell lymphoma-extra large; CypD, cyclophilin D; ER, endoplasmic reticulum; GRP75, mortalin; IP3R, inositol 1,4,5-trisphosphate receptor; MICU1, mitochondrial $\mathrm{Ca}^{2+}$ uptake 1 ; MCU, mitochondrial $\mathrm{Ca}^{2+}$ uniporter; MFN2, mitofusin 2; MT, mitochondrion; ORP, oxysterol-binding protein; PML, promyelocytic leukemia protein; PP2a, protein phosphatase 2a; PTEN, phosphatase and tensin homolog deleted on chromosome 10; PTPIP51, phosphatase-interacting protein 51; SERCA, sarco/endoplasmatic reticulum $\mathrm{Ca}^{2+}$ ATPase; VAPB, vesicle-associated membrane protein-associated protein $\mathrm{B}$; VDAC, voltage-dependent anion channel.

between Bcl-2 and IP3Rs suggest that the role of Bcl-2 in controlling $\mathrm{Ca}^{2+}$ signaling is to suppress excessive proapoptotic $\mathrm{Ca}^{2+}$ cues but to support prosurvival $\mathrm{Ca}^{2+}$ oscillations (Fig. 2) [141]. Therefore, dysregulation of Bcl-2 expression is a triggering event in various cancers, including chronic lymphocytic leukemia (CLL), diffuse large B-cell lymphoma (DL-BCL), non-small cell lung carcinoma, multiple myeloma, follicular lymphoma and small cell lung cancer [144-148]. Selective treatment with a Bcl-2/IP3R inhibitor (BIRD-2) has shown promising results in the treatment of B-cell cancer [149], small cell lung cancer [150], chronic lymphocytic leukemia [151], multiple myeloma and follicular lymphoma [152]. Bcl-XL is another important antiapoptotic protein belonging to the Bcl-2 family and frequently overexpressed in tumors. Bcl-XL at the OMM has been proposed to modulate apoptosis by controlling mitochondrial membrane permeability (via VDAC) and regulating the release of cytochrome c [153,154]. Increased levels of $\mathrm{Bcl}-\mathrm{XL}$ have been detected in tumors where cell survival is promoted at the expense of apoptosis, such as multiple myeloma; melanoma; glioblastoma; and prostate, colorectal, non-small-cell lung and pancreatic cancers [155-158]. Similar to Bcl-2, Bcl-XL directly binds the IP3R channel, regulating IP3R $\mathrm{Ca}^{2+}$ flux characteristics (Fig. 2) [159]. Accordingly, Bcl-XL inhibitors (WEHI-539; A-1155463; A-1331852) are used in therapies for B-cell lymphomas and various solid tumors $[160,161]$.

Phosphorylated K-Ras interacts with IP3R1 along with Bcl-XL, 
preventing the sensitization of channels, thus decreasing mitochondrial $\mathrm{Ca}^{2+}$ uptake and, in turn, inducing autophagy (Fig. 2) [162]. Ras is a small GTPase that translocates from the PM to internal membranes, including the ER and mitochondria, in response to stimuli [163]. At MAMs, oncogenic H-Ras affects $\mathrm{Ca}^{2+}$ transfer from the ER to mitochondria in order to induce apoptosis evasion [23]. In colorectal cancer cells, oncogenic K-Ras alters the expression of IP3Rs, reducing $\mathrm{Ca}^{2+}$ release to mitochondria from the ER in order to allow cells to evade $\mathrm{Ca}^{2+}$-mediated proapoptotic signals [164]. Indeed, Ras-driven mitochondrial dysfunction causes metabolic and redox changes that sustain tumorigenesis [165].

The protooncogene Akt phosphorylates all isoforms of IP3R at a conserved consensus sequence, blocking $\mathrm{IP}_{3} \mathrm{R}$-mediated $\mathrm{Ca}^{2+}$ efflux from the ER to mitochondria, thus allowing cells to evade cell death $[166,167]$. The main Akt pathway, the phosphatidylinositol-3 kinase $\left(\mathrm{PI}_{3} \mathrm{~K}\right)$-Akt pathway, is one of the most commonly dysregulated pathways in tumorigenesis, exhibiting somatic mutations, copy number alterations, aberrant epigenetic regulation and increased expression at the expense of Akt [168]. In mitochondria, Akt is responsible for phosphorylating the MCU regulatory subunit MICU1, which impairs MICU1 processing and stability, culminating in aberrant mitochondrial $\mathrm{Ca}^{2+}$ levels, ROS production and tumor progression [169]. Additionally, the Akt activator mTORC2 is localized at the ER/mitochondria compartment, where, with Akt, it is responsible for the maintenance of mitochondrial homeostasis along with the regulation of $\mathrm{IP}_{3} \mathrm{R}$ phosphorylation and thus $\mathrm{Ca}^{2+}$ flux (Fig. 2) [111]. Interestingly, melatonin, the hormone known to regulate sleep-wake cycle, exhibits anticancer effects, reducing cancer cell proliferation by modulating the phosphorylation of Akt [170]. Thus, due to its safety, nontoxicity, and effectiveness represent a promising adjuvant therapy for cancer treatment $[171,172]$.

The tumor suppressors PTEN and PML have been shown to be localized at MAMs. Mutations in phosphatase and tensin homolog deleted on chromosome 10 (PTEN) are present in many primary human tumors [173], resulting in the constitutive activation of the $\mathrm{PI}_{3} \mathrm{~K}$-Akt pathway due to loss of PTEN function [174]. In addition, the role of PTEN in tumorigenesis has been associated with its ability to increase $\mathrm{Ca}^{2+}$ release from the ER via IP3Rs, thus restoring cellular sensitivity to $\mathrm{Ca}^{2+}$ mediated proapoptotic stimuli through IP3R phosphorylation [175]. Furthermore, PTEN competes with F-box/LRR-repeat protein 2 (FBXL2), a mediator of protein ubiquitination and degradation, for IP3R3 binding, decreasing proteasomal degradation of IP3R3 (Fig. 2) [176]. This antagonistic action of PTEN is responsible for maintaining IP3R3mediated $\mathrm{Ca}^{2+}$ influx to mitochondria, thus preserving cellular responsiveness to proapoptotic stimuli. PML, a tumor suppressor mainly known for its role as a transcription factor at the nuclear level, is another protein that interacts with Akt. The presence of PML at MAMs regulates apoptosis through Akt dephosphorylation by protein phosphatase 2a (PP2A), inhibiting IP3R3 phosphorylation (Fig. 2) [177]. The distribution of PML at MAMs may be controlled by the tumor suppressor p53 [178]. p53 is one of the most extensively studied transcription factor proteins in cancer research and is normally localized in the cytosol and at mitochondria in response to stressors, such as chemotherapy or oxidative stress [179]. However, p53 may accumulate in the ER, affecting $\mathrm{Ca}^{2+}$ transfer via SERCA activity [180]. GRP75 is a cytosolic inactivator of p53 [181] that affects the functionality of p53 by retaining it in the cytoplasm, leading to the downregulation of p53 target genes [182]. Accordingly, GRP75 overexpression has been associated with liver cancer metastasis and has been linked with cisplatin resistance in ovarian cancer $[183,184]$. These findings indicate that GRP75 is a novel protein target for tumor therapies. Administration of anti-GRP75 molecules leads to tumor growth suppression, and small molecule inhibitors (MKT-077 and CAPE) that can prevent p53-GRP75 complex formation have recently been discovered [185].

VDAC interacts with different cytosolic proteins, including Bcl-2 family members, to mediate metabolic communication and signaling between the cytosol and mitochondria [186]. The interaction of VDAC1 with apoptosis-regulating proteins highlights the possible role of this protein in tumor progression. Indeed, VDAC1 has been shown to modulate mitochondrial metabolism in cancer cells, and its expression levels are different in tumor cells and normal tissues (reviewed in [186]). Silencing VDAC1 expression in cancer cell lines reduces the ATP level and the $\Delta \Psi_{\mathrm{m}}$ value, suggesting a limited exchange of metabolites between mitochondria and the cytosol that results in decreased migration and the inhibition of cancer cell proliferation [187]. Therefore, VDAC1 is a novel target for cancer therapies via apoptosis regulation [188].

The final player in mitochondrial $\mathrm{Ca}^{2+}$ uptake is MCU, the overexpression of which has been associated with several different tumor types, such as colorectal, ovarian, prostate and breast, and correlated with tumor size, migration ability and invasion ability [189]. Interestingly, miR-25, the first microRNA identified to target MCU, is overexpressed in colon cancer. In this scenario, MCU is silenced and mitochondrial $\mathrm{Ca}^{2+}$ uptake is reduced, leading to resistance to proapoptotic stimuli that can be reversed by anti-miR-25 expression [190]. MCU is also a downstream target of miR-340, which inhibits motility and the switch from OXPHOS to glycolysis (the Warburg effect) in breast cancer cells [191]. The MCU inhibitor mitoxantrone, an anthracenedione-derived agent, has been used to treat hematological malignancies, but its antineoplastic effect is independent of MCU inhibition [192]. Recently, new compounds, including DS16570511 and Ru265, have been identified as specific, freely PM-permeable MCU inhibitors, but to date, no evidence for their utility in cancer treatment has been reported [193,194]. Fhit is a tumor suppressor that controls the affinity of MCU to physiological and proapoptotic $\mathrm{Ca}^{2+}$-dependent stimuli [195]. Fhit acts as a tumor suppressor by increasing the number of mitochondrial $\mathrm{Ca}^{2+}$ hotspots - the initial sites of $\mathrm{Ca}^{2+}$ uptake in the mitochondrial matrix - to enhance the susceptibility of cells to apoptosis.

Importantly, the $\mathrm{Ca}^{2+}$ transfer between the $\mathrm{ER}$ and mitochondria is also affected by aberrant coupling of these two membranes. For instance, alterations in PACS-2 expression have been found in non-small cell lung cancer (NSCLC) [196]. Furthermore, changes in mitochondrial morphology, such as mitochondrial fragmentation, have been reported to protect against $\mathrm{Ca}^{2+}$-dependent apoptosis, limiting mitochondrial $\mathrm{Ca}^{2+}$ overload by preventing the propagation of $\mathrm{Ca}^{2+}$ waves within the matrix. This dysregulation results in metabolic changes in cancer cells, inducing the Warburg effect [197]. Moreover, MFN2 has also been proven to mediate mTORC2-Akt signaling, indicating another critical contribution of MFN2 in suppressing tumor progression through direct inhibition of this pathway [198]. Accordingly, decreased expression of MFN2 has been reported in several tumors, such as liver, colorectal, lung and breast [198-201]. Genome-wide analysis of different human breast cancer cell lines and clinical specimens revealed that in the context of this tumor, not only is MFN2 expression downregulated but also the expression of the ER resident VAPB is often amplified or overexpressed [202]. VAPB, as stated before, is involved in the coupling of the ER with different cellular organelles, such as mitochondria, the Golgi apparatus or endolysosomes, thus regulating protein secretion and vesicle trafficking. Alterations in these processes may underlie the receptor localization and growth factor secretion that allow tumor growth [203]. PTPIP51 is another protein responsible for ER-mitochondrial coupling and was found to be overexpressed in glioblastoma, prostate cancer, breast cancer and keratinocyte carcinoma [204-207]. The involvement of PTPIP51 in tumorigenesis is mainly due to its multiple roles in cellular physiology, which involve the regulation of not only ER-mitochondria contact sites and consequently apoptosis and autophagy but also cellular differentiation, cell motility and cytoskeleton formation. Interestingly, PTPIP51 has been shown to interact with ORP5 and ORP8 at MAMs, regulating mitochondrial morphology and respiratory function [44]. ORPs play a role in the regulation of different cell signaling pathways through the mediation of membrane 
contacts (ER-PM and ER-mitochondria), mainly controlling the transport of lipids and PS. Therefore, it is unsurprising that alterations in ORPs expression are linked to cancer development [208]. Specifically, ORP5 upregulation is related to increased invasion and poor prognosis in pancreatic cancer patients [209], while ORP8 downregulation has been observed in hepatocellular carcinoma cell lines [210]. Whether the involvement of ORPs in cancer development is strictly linked to lipid and PS transport and not to dysregulated $\mathrm{Ca}^{2+}$ transfer between compartments remains to be investigated. Notably, ORP dysregulation affects both the Akt and mTOR pathways in cells, suggesting the possible involvement of $\mathrm{Ca}^{2+}$ modulation.

\subsection{ER-plasma membrane interface}

PM-ER junctions are critically implicated in controlling the $\left[\mathrm{Ca}^{2+}\right]_{\mathrm{cyt}}$ via the regulation of $\mathrm{Ca}^{2+}$ channels in either the PM or the ER membrane.

In different types of tumors, the expression levels of SOCE components are altered. The resulting dysregulated $\mathrm{Ca}^{2+}$ influx affects tumorigenesis by increasing angiogenesis, promoting cell cycle progression and metastasis and affecting apoptosis [211]. Since the first reported mutation of STIM1 in human rhabdomyosarcoma, an increasing number of SOCE component alterations specific to cancer types and stages have been reported [212-214]. For instance, STIM1 levels are upregulated in colorectal cancer, clear cell renal cell carcinoma (ccRCC), and early-stage cervical cancer and are positively correlated with poor prognosis due to increased tumor size, invasion and metastasis [215-217]. Overexpression of STIM1 and Orai1 affects cell cycle progression by altering the expression of cell cycle regulatory proteins [211]. Moreover, SOCE regulates cell migration by generating $\mathrm{Ca}^{2+}$ pulses at the leading edge of cells, thus promoting myosin IImediated directional movements via the activation of focal adhesion kinases [218]. Accordingly, downregulation of STIM1 and Orai1, either pharmacologically (e.g., by the SOCE inhibitor SKF-96365) or with siRNA, blocks cellular proliferation and invasion in several types of cancer [215,219-221].

Cav1, localized at the caveolar microdomain of the PM and normally dysregulated in cancer cells, is another protein involved in the regulation of $\mathrm{Ca}^{2+}$ flux. Cav1 has both antitumorigenic and protumorigenic effects. For example, the gene encoding cav1 is localized in a known tumor suppressor locus and is deleted in different types of cancer [222]. However, cav1 has been demonstrated to influence tumor development in bladder, colon, liver, stomach, breast and lung cancer by regulating $\mathrm{Ca}^{2+}$ homeostasis and migration [223-226]. Interestingly, cav1-mediated variations in intracellular $\mathrm{Ca}^{2+}$ levels are induced by the oncogene Ras, leading to mitochondrial alterations [23]. Cav1 antagonists such as nitrendipine, nifedipine and verapamil are routinely included in therapies for different disorders [227], indicating their potential use as cancer therapies.

The translocation and activity of sphingosine kinase 1 (SK1) are controlled by $\mathrm{Ca}^{2+}$ in caveolae [228]. Oncogenic SK1 expression induces an increase in the $\mathrm{Ca}^{2+}$ concentration in caveolae, which dysregulates cytoskeletal and focal adhesion assembly, leading to altered cellular migratory capacity [9].

ER/PM contact sites, and therefore $\mathrm{Ca}^{2+}$ exchange, are also modulated by E-Syt. Notably, E-Syt1 is a target of the oncogenic lung cancer fusion kinase CD74-ROS, which is commonly expressed in NSCLC [229]. Phosphorylation of E-Syt1 on tyrosine 993 (Y993) by CD74-ROS leads to increased tumor invasiveness. This site in E-Syt1, conserved in E-Syt2 and E-Syt3, is also phosphorylated in other cancer cell lines and in human NSCLC biopsies [230]. Therefore, E-Syts and their posttranslational regulation might represent a possible target for cancer therapy [51].

\subsection{ER-endolysosome interface}

Another important platform for $\mathrm{Ca}^{2+}$ signaling is the ER-endolysosome platform. At this interface, multiple cellular functions, such as endocytic trafficking, autophagy, and lysosomal function, are strictly regulated. Alterations in this interface influence cell metabolism and fate. Accordingly, lysosomes are widely acknowledged to be involved in maintaining the tumorigenic process and sustaining cell proliferation, metastasis and angiogenesis by providing cancer cells with energy and metabolic precursors [231]. In addition, lysosomes and endolysosomes are responsible for extracellular matrix remodeling, which is essential for angiogenetic processes, and are involved in mediating drug resistance (i.e., to chemotherapies) [232]. Studies aimed at assessing whether the endolysosome-associated $\mathrm{Ca}^{2+}$ machinery is involved in tumorigenesis have revealed that altered expression of the two-pore channels or the transient receptor potential channels is associated with malignant transformation [233]. For instance, increased expression of both TPC1 and TPC2 is associated with increased migration and metastasis in different cancer cell lines, and selective targeting of both genes reduces cell adhesion and migration in vitro [234]. TRPML2 is the only member of the transient receptor potential channel family to have been associated with tumor progression [235]. TRPML2 mRNA and protein are expressed in glioma tissues, and their levels are positively correlated with the malignant transformation from pilocytic astrocytoma (grade I) to glioblastoma (grade IV). In addition, TRPML2 overexpression results in cellular resistance to apoptosis through the phosphorylation of Akt and ERK 1/2 and blockade of caspase-3 [236]. Accordingly, TRPML-2 silencing restored apoptotic cell death in glioblastoma cells [236]. These findings suggest that endolysosomal $\mathrm{Ca}^{2+}$ signals could effectively be modulated, acting at both at the TPC and TRPM levels, and may be a promising target for cancer therapies [235].

\section{Conclusion}

Intracellular organelles are not independent but are structurally and functionally interconnected to allow reciprocal regulation of $\mathrm{Ca}^{2+}$. Interorganelle platforms shelter various proteins with different functions, and several play a pivotal role in $\mathrm{Ca}^{2+}$ signaling and lipid transfer. The structure and function of these connections are dynamically regulated by nutritional and environmental cues, influencing cellular metabolism and thus allowing cells to adapt according to physiological and pathological requirements. Alterations in the interorganellar $\mathrm{Ca}^{2+}$ signaling directly affect cellular metabolism and, as expected, are associated with pathologies [237,238], including cancer. The importance of interorganelle platforms in regulating spatiotemporal $\mathrm{Ca}^{2+}$ signaling in cancer is further strengthened by multiple lines of evidence indicating that different oncogenes and tumor suppressors actively shape interorganelle platforms to alter $\mathrm{Ca}^{2+}$ communication between the organelles.

These interorganelle platforms are quickly becoming recognized as hotspots for metabolic decision-making and as possible targets for future antitumor approaches.

Interorganellar $\mathrm{Ca}^{2+}$ communication between cellular organelles is a new concept in biomedicine. The expanding roles of interorganelle $\mathrm{Ca}^{2+}$ signaling in cell physiology have encouraged researchers to return to apparently "easy" questions: What proteins reside in interorganelle platforms? How are these platforms organized to transfer $\mathrm{Ca}^{2+}$ between organelles?

To date, few studies have analyzed the protein content in interorganelle fractions or the interorganellar $\mathrm{Ca}^{2+}$ flux, providing few answers to these questions. Currently, researchers realize that the understanding of the form and function of interorganelle domains is limited.

Pioneering studies have developed tools to measure ER-mitochondrial coupling by mediating dimerization-dependent fluorescent proteins and the $\mathrm{Ca}^{2+}$ concentrations at the interorganelle interface 
$[18,239]$; however, these tools require further refinement. The extension of these approaches to other interorganelle platforms has generated new tools for $\mathrm{Ca}^{2+}$ measurement that allow the investigation of intracellular $\mathrm{Ca}^{2+}$ microdomains in caveolae on the PM and the extent of $\mathrm{Ca}^{2+}$ filling of the lysosomal lumen $[9,67]$. The ER-mitochondria interface is the most extensively studied interorganelle platform, but to date, only three proteomics studies have been performed, with puzzling results [20-22].

The principal difficulty in such studies is related to the dynamic nature of these interorganelle platforms; current evidence shows the ways in which the protein and lipid composition of these structures change in response to different stimuli and cellular requirements.

The character of the lipid components in interorganelle platforms is crucial not only for the membrane stability and fluidity but also for $\mathrm{Ca}^{2+}$ transfer between organelles. Binding of $\mathrm{Ca}^{2+}$ to lipid membranes significantly alters the membranes by reducing their hydration, lipid mobility, and lateral interlipid distance. This local conformational membrane remodeling plays a significant role in the modulation of lipid-protein interactions as well as membrane-membrane associations [240]. Conversely, proteins may be lipidated; for example, IP3R is palmitoylated by the ZDHHC-SELENOK complex [241]. Reducing the palmitoylation of IP3R decreases IP3-stimulated $\mathrm{Ca}^{2+}$ release from the $\mathrm{ER}$, leading to destabilization of the IP3R protein. This posttranslational modification is essential for the oncogenic function of approximately eighty cancer-associated proteins (both oncogenes and tumor suppressors); palmitoylation increases the affinity of these proteins for membranes (e.g., the Ras family) [242].

Another difficulty in this research area is the isolation of a pure interorganelle fraction; specific and effective protocols exist but do not guarantee a high level of purity. A contaminated fraction may generate spurious, difficult-to-interpret results.

However, further studies are needed to better understand the purpose and regulatory mechanisms of interorganellar $\mathrm{Ca}^{2+}$ signaling. Many fluorescent protein-based applications, engineered tools and new biochemical approaches are available for use in a wide variety of livecell molecular imaging and biochemical applications to determine fusion protein localization, image dynamic changes in membrane proteins and visualize interorganellar $\mathrm{Ca}^{2+}$ dynamics.

\section{Acknowledgments}

PP is grateful to Camilla degli Scrovegni for continuous support. The Signal Transduction laboratory is supported by the following: local funds from the University of Ferrara, FIR-2017, and the Italian Ministry of Health (GR-2016-02364602) to AR; and by the Italian Association for Cancer Research (AIRC, IG-18624), Telethon (GGP11139B), and local funds from the University of Ferrara to PP. CG is supported by local funds from the University of Ferrara, the Italian Association for Cancer Research (AIRC: IG-19803), the Italian Ministry of Health (GR-201302356747), and by a Fondazione Cariplo grant. MRW was supported by the Polish National Science Centre grant UMO-2018/29/B/NZ1/00589 for M.R.W.. Moreover, MRW gratefully acknowledge the financial support for this research from the FOIE GRAS and mtFOIE GRAS projects. These projects received funding from the European Union's Horizon 2020 Research and Innovation programme under the Marie Skłodowska-Curie Grant Agreement No. 722619 (FOIE GRAS) and Grant Agreement No. 734719 (mtFOIE GRAS).

\section{References}

[1] C. Giorgi, A. Danese, S. Missiroli, S. Patergnani, P. Pinton, Calcium dynamics as a machine for decoding signals, Trends Cell Biol. 28 (4) (2018) 258-273.

[2] M.J. Berridge, Calcium microdomains: organization and function, Cell Calcium 40 (5-6) (2006) 405-412.

[3] A.A. Rowland, G.K. Voeltz, Endoplasmic reticulum-mitochondria contacts: function of the junction, Nat. Rev. Mol. Cell Biol. 13 (10) (2019) 607-625.

[4] E.M. Lynes, T. Simmen, Urban planning of the endoplasmic reticulum (ER): how diverse mechanisms segregate the many functions of the ER, Biochim. Biophys. Acta 1813 (10) (2019) 1893-1905.

[5] J. Liou, M.L. Kim, W.D. Heo, J.T. Jones, J.W. Myers, J.E. Ferrell Jr., T. Meyer, STIM is a Ca2 + sensor essential for Ca2 +-store-depletion-triggered Ca2 + influx, Curr. Biol. 15 (13) (2005) 1235-1241.

[6] T. Fujimoto, Calcium pump of the plasma membrane is localized in caveolae, J. Cell Biol. 120 (5) (1993) 1147-1157.

[7] T. Fujimoto, S. Nakade, A. Miyawaki, K. Mikoshiba, K. Ogawa, Localization of inositol 1,4,5-trisphosphate receptor-like protein in plasmalemmal caveolae, J. Cell Biol. 119 (6) (1992) 1507-1513.

[8] M. Isshiki, R.G. Anderson, Function of caveolae in Ca2 + entry and Ca2 +-dependent signal transduction, Traffic 4 (11) (2003) 717-723.

[9] I. Pulli, T. Blom, C. Lof, M. Magnusson, A. Rimessi, P. Pinton, K. Tornquist, A nove] chimeric aequorin fused with caveolin-1 reveals a sphingosine kinase 1-regulated $\mathrm{Ca}(2)(+)$ microdomain in the caveolar compartment, Biochim. Biophys. Acta 1853 (9) (2015) 2173-2182.

[10] C. Giorgi, S. Missiroli, S. Patergnani, J. Duszynski, M.R. Wieckowski, P. Pinton, Mitochondria-associated membranes: composition, molecular mechanisms, and physiopathological implications, Antioxid. Redox Signal. 22 (12) (2015) 995-1019.

[11] S. Marchi, S. Patergnani, S. Missiroli, G. Morciano, A. Rimessi, M.R. Wieckowski, C. Giorgi, P. Pinton, Mitochondrial and endoplasmic reticulum calcium homeostasis and cell death, Cell Calcium 69 (2018) 62-72.

[12] C. Giorgi, S. Marchi, P. Pinton, The machineries, regulation and cellular functions of mitochondrial calcium, Nat. Rev. Mol. Cell Biol. 19 (11) (2018) 713-730.

[13] D.E. Copeland, A.J. Dalton, An association between mitochondria and the endoplasmic reticulum in cells of the pseudobranch gland of a teleost, J. Biophys. Biochem. Cytol. 5 (3) (1959) 393-396.

[14] J.E. Vance, Phospholipid synthesis in a membrane fraction associated with mitochondria, J. Biol. Chem. 265 (13) (1990) 7248-7256.

[15] R. Rizzuto, P. Pinton, W. Carrington, F.S. Fay, K.E. Fogarty, L.M. Lifshitz, R.A. Tuft, T. Pozzan, Close contacts with the endoplasmic reticulum as determinants of mitochondrial Ca2 + responses, Science 280 (5370) (1998) 1763-1766.

[16] M.R. Wieckowski, C. Giorgi, M. Lebiedzinska, J. Duszynski, P. Pinton, Isolation of mitochondria-associated membranes and mitochondria from animal tissues and cells, Nat. Protoc. 4 (11) (2009) 1582-1590.

[17] G. Csordas, C. Renken, P. Varnai, L. Walter, D. Weaver, K.F. Buttle, T. Balla, C.A. Mannella, G. Hajnoczky, Structural and functional features and significance of the physical linkage between ER and mitochondria, J. Cell Biol. 174 (7) (2006) 915-921.

[18] G. Csordas, P. Varnai, T. Golenar, S. Roy, G. Purkins, T.G. Schneider, T. Balla, G. Hajnoczky, Imaging interorganelle contacts and local calcium dynamics at the ER-mitochondrial interface, Mol. Cell 39 (1) (2010) 121-132.

[19] J.R. Friedman, L.L. Lackner, M. West, J.R. DiBenedetto, J. Nunnari, G.K. Voeltz, ER tubules mark sites of mitochondrial division, Science 334 (6054) (2011) 358-362.

[20] C.N. Poston, E. Duong, Y. Cao, C.R. Bazemore-Walker, Proteomic analysis of lipid raft-enriched membranes isolated from internal organelles, Biochem. Biophys. Res. Commun. 415 (2) (2011) 355-360.

[21] A. Zhang, R.L. Hildreth, A.M. Colberg-Poley, Human cytomegalovirus inhibits apoptosis by proteasome-mediated degradation of Bax at endoplasmic reticulummitochondrion contacts, J. Virol. 87 (10) (2013) 5657-5668.

[22] A. Sala-Vila, I. Navarro-Lerida, M. Sanchez-Alvarez, M. Bosch, C. Calvo, J.A. Lopez, E. Calvo, C. Ferguson, M. Giacomello, A. Serafini, L. Scorrano, J.A. Enriquez, J. Balsinde, R.G. Parton, J. Vazquez, A. Pol, M.A. Del Pozo, Interplay between hepatic mitochondria-associated membranes, lipid metabolism and caveolin-1 in mice, Sci. Rep. 6 (2016) 27351.

[23] A. Rimessi, S. Marchi, S. Patergnani, P. Pinton, H-Ras-driven tumoral maintenance is sustained through caveolin-1-dependent alterations in calcium signaling, Oncogene 33 (18) (2014) 2329-2340.

[24] B. Kornmann, E. Currie, S.R. Collins, M. Schuldiner, J. Nunnari, J.S. Weissman, P. Walter, An ER-mitochondria tethering complex revealed by a synthetic biology screen, Science 325 (5939) (2009) 477-481.

[25] S. Lahiri, J.T. Chao, S. Tavassoli, A.K. Wong, V. Choudhary, B.P. Young, C.J. Loewen, W.A. Prinz, A conserved endoplasmic reticulum membrane protein complex (EMC) facilitates phospholipid transfer from the ER to mitochondria, PLoS Biol. 12 (10) (2014) e1001969.

[26] Y. Hirabayashi, S.K. Kwon, H. Paek, W.M. Pernice, M.A. Paul, J. Lee, P. Erfani, A. Raczkowski, D.S. Petrey, L.A. Pon, F. Polleux, ER-mitochondria tethering by PDZD8 regulates $\mathrm{Ca}(2+)$ dynamics in mammalian neurons, Science 358 (6363) (2017) 623-630.

[27] T. Simmen, J.E. Aslan, A.D. Blagoveshchenskaya, L. Thomas, L. Wan, Y. Xiang, S.F. Feliciangeli, C.H. Hung, C.M. Crump, G. Thomas, PACS-2 controls endoplasmic reticulum-mitochondria communication and Bid-mediated apoptosis, EMBO J. 24 (4) (2005) 717-729.

[28] A.P. Arruda, B.M. Pers, G. Parlakgul, E. Guney, K. Inouye, G.S. Hotamisligil, Chronic enrichment of hepatic endoplasmic reticulum-mitochondria contact leads to mitochondrial dysfunction in obesity, Nat. Med. 20 (12) (2014) 1427-1435.

[29] M. Kottgen, T. Benzing, T. Simmen, R. Tauber, B. Buchholz, S. Feliciangeli, T.B. Huber, B. Schermer, A. Kramer-Zucker, K. Hopker, K.C. Simmen, C.C. Tschucke, R. Sandford, E. Kim, G. Thomas, G. Walz, Trafficking of TRPP2 by PACS proteins represents a novel mechanism of ion channel regulation, EMBO J. 24 (4) (2005) 705-716.

[30] N. Myhill, E.M. Lynes, J.A. Nanji, A.D. Blagoveshchenskaya, H. Fei, K. Carmine Simmen, T.J. Cooper, G. Thomas, T. Simmen, The subcellular distribution of calnexin is mediated by PACS-2, Mol. Biol. Cell 19 (7) (2008) 2777-2788. 
[31] O.M. de Brito, L. Scorrano, Mitofusin 2 tethers endoplasmic reticulum to mitochondria, Nature 456 (7222) (2008) 605-610.

[32] R. Filadi, E. Greotti, G. Turacchio, A. Luini, T. Pozzan, P. Pizzo, Mitofusin 2 ablation increases endoplasmic reticulum-mitochondria coupling, Proc. Natl. Acad. Sci. U. S. A. 112 (17) (2015) E2174-81.

[33] P. Cosson, A. Marchetti, M. Ravazzola, L. Orci, Mitofusin-2 independent juxtaposition of endoplasmic reticulum and mitochondria: an ultrastructural study, PLoS One 7 (9) (2012) e46293.

[34] G. Szabadkai, K. Bianchi, P. Varnai, D. De Stefani, M.R. Wieckowski, D. Cavagna, A.I. Nagy, T. Balla, R. Rizzuto, Chaperone-mediated coupling of endoplasmic reticulum and mitochondrial Ca2 + channels, J. Cell Biol. 175 (6) (2006) 901-911.

[35] J. Rieusset, J. Fauconnier, M. Paillard, E. Belaidi, E. Tubbs, M.A. Chauvin, A. Durand, A. Bravard, G. Teixeira, B. Bartosch, M. Michelet, P. Theurey, G. Vial, M. Demion, E. Blond, F. Zoulim, L. Gomez, H. Vidal, A. Lacampagne, M. Ovize, Disruption of calcium transfer from ER to mitochondria links alterations of mitochondria-associated ER membrane integrity to hepatic insulin resistance, Diabetologia 59 (3) (2016) 614-623.

[36] E. Tubbs, P. Theurey, G. Vial, N. Bendridi, A. Bravard, M.A. Chauvin, J. Ji-Cao, F. Zoulim, B. Bartosch, M. Ovize, H. Vidal, J. Rieusset, Mitochondria-associated endoplasmic reticulum membrane (MAM) integrity is required for insulin signaling and is implicated in hepatic insulin resistance, Diabetes 63 (10) (2014) 3279-3294.

[37] M. Paillard, E. Tubbs, P.A. Thiebaut, L. Gomez, J. Fauconnier, C.C. Da Silva, G. Teixeira, N. Mewton, E. Belaidi, A. Durand, M. Abrial, A. Lacampagne, J. Rieusset, M. Ovize, Depressing mitochondria-reticulum interactions protects cardiomyocytes from lethal hypoxia-reoxygenation injury, Circulation 128 (14) (2013) 1555-1565.

[38] R. Stoica, K.J. De Vos, S. Paillusson, S. Mueller, R.M. Sancho, K.F. Lau, G. VizcayBarrena, W.L. Lin, Y.F. Xu, J. Lewis, D.W. Dickson, L. Petrucelli, J.C. Mitchell, C.E. Shaw, C.C. Miller, ER-mitochondria associations are regulated by the VAPBPTPIP51 interaction and are disrupted by ALS/FTD-associated TDP-43, Nat Commun. 5 (2014) 3996.

[39] K.J. De Vos, G.M. Morotz, R. Stoica, E.L. Tudor, K.F. Lau, S. Ackerley, A. Warley, C.E. Shaw, C.C. Miller, VAPB interacts with the mitochondrial protein PTPIP51 to regulate calcium homeostasis, Hum. Mol. Genet. 21 (6) (2012) 1299-1311.

[40] P. Gomez-Suaga, S. Paillusson, R. Stoica, W. Noble, D.P. Hanger, C.C.J. Miller, The ER-Mitochondria tethering complex VAPB-PTPIP51 regulates autophagy, Curr. Biol. 27 (3) (2017) 371-385.

[41] S. Mogelsvang, B.J. Marsh, M.S. Ladinsky, K.E. Howell, Predicting function from structure: 3D structure studies of the mammalian Golgi complex, Traffic 5 (5) (2004) 338-345.

[42] K. Kumagai, M. Kawano-Kawada, K. Hanada, Phosphoregulation of the ceramide transport protein CERT at serine 315 in the interaction with VAMP-associated protein (VAP) for inter-organelle trafficking of ceramide in mammalian cells, $\mathrm{J}$. Biol. Chem. 289 (15) (2014) 10748-10760.

[43] J. Chung, F. Torta, K. Masai, L. Lucast, H. Czapla, L.B. Tanner, P. Narayanaswamy, M.R. Wenk, F. Nakatsu, P. De Camilli, Intracellular transport. PI4P/phosphatidylserine countertransport at ORP5- and ORP8-mediated ER-plasma membrane contacts, Science 349 (6246) (2015) 428-432.

[44] R. Galmes, A. Houcine, A.R. van Vliet, P. Agostinis, C.L. Jackson, F. Giordano, ORP5/ORP8 localize to endoplasmic reticulum-mitochondria contacts and are involved in mitochondrial function, EMBO Rep. 17 (6) (2016) 800-810.

[45] W. Montagna, Histology and cytochemistry of human skin. XI. The distribution of beta-glucuronidase, J. Biophys. Biochem. Cytol. 3 (3) (1957) 343-348.

[46] M.J. Phillips, G.K. Voeltz, Structure and function of ER membrane contact sites with other organelles, Nat. Rev. Mol. Cell Biol. 17 (2) (2016) 69-82.

[47] L. Orci, M. Ravazzola, M. Le Coadic, W.W. Shen, N. Demaurex, P. Cosson, From the Cover: STIM1-induced precortical and cortical subdomains of the endoplasmic reticulum, Proc. Natl. Acad. Sci. U. S. A. 106 (46) (2009) 19358-19362.

[48] R. Fernandez-Busnadiego, Y. Saheki, P. De Camilli, Three-dimensional architecture of extended synaptotagmin-mediated endoplasmic reticulum-plasma membrane contact sites, Proc. Natl. Acad. Sci. U. S. A. 112 (16) (2015) E2004-13.

[49] J.M. Suski, M. Lebiedzinska, A. Wojtala, J. Duszynski, C. Giorgi, P. Pinton, M.R. Wieckowski, Isolation of plasma membrane-associated membranes from rat liver, Nat. Protoc. 9 (2) (2014) 312-322.

[50] A. Toulmay, W.A. Prinz, A conserved membrane-binding domain targets proteins to organelle contact sites, J. Cell. Sci. 125 (Pt 1) (2012) 49-58.

[51] C. Herdman, T. Moss, Extended-Synaptotagmins (E-Syts); the extended story, Pharmacol. Res. 107 (2016) 48-56.

[52] C.L. Chang, T.S. Hsieh, T.T. Yang, K.G. Rothberg, D.B. Azizoglu, E. Volk, J.C. Liao, J. Liou, Feedback regulation of receptor-induced Ca2 + signaling mediated by ESyt1 and Nir2 at endoplasmic reticulum-plasma membrane junctions, Cell Rep. 5 (3) (2013) 813-825.

[53] M. Prakriya, R.S. Lewis, Store-operated calcium channels, Physiol. Rev. 95 (4) (2015) 1383-1436.

[54] T. Simmen, M. Tagaya, Organelle communication at membrane contact sites (MCS): from curiosity to center stage in cell biology and biomedical research, Adv. Exp. Med. Biol. 997 (2017) 1-12.

[55] B. Pani, B.B. Singh, Lipid rafts/caveolae as microdomains of calcium signaling, Cell Calcium 45 (6) (2009) 625-633.

[56] J. Maleth, S. Choi, S. Muallem, M. Ahuja, Translocation between PI(4,5)P2-poor and PI(4,5)P2-rich microdomains during store depletion determines STIM1 conformation and Orail gating, Nat. Commun. 5 (2014) 5843.

[57] S. Sharma, A. Quintana, G.M. Findlay, M. Mettlen, B. Baust, M. Jain, R. Nilsson, A. Rao, P.G. Hogan, An siRNA screen for NFAT activation identifies septins as coordinators of store-operated Ca2 + entry, Nature 499 (7457) (2013) 238-242.
[58] N. Rocha, C. Kuijl, R. van der Kant, L. Janssen, D. Houben, H. Janssen, W. Zwart, J. Neefjes, Cholesterol sensor ORP1L contacts the ER protein VAP to control Rab7RILP-p150 glued and late endosome positioning, J. Cell Biol. 185 (7) (2009) 1209-1225.

[59] S. Patel, R. Docampo, Acidic calcium stores open for business: expanding the potential for intracellular Ca2 + signaling, Trends Cell Biol. 20 (5) (2010) $277-286$.

[60] B. Lelouvier, R. Puertollano, Mucolipin-3 regulates luminal calcium, acidification, and membrane fusion in the endosomal pathway, J. Biol. Chem. 286 (11) (2011) 9826-9832.

[61] A.J. Morgan, F.M. Platt, E. Lloyd-Evans, A. Galione, Molecular mechanisms of endolysosomal Ca2 + signalling in health and disease, Biochem. J. 439 (3) (2011) 349-374.

[62] K. Abe, R. Puertollano, Role of TRP channels in the regulation of the endosomal pathway, Physiology (Bethesda) 26 (1) (2011) 14-22.

[63] M. Ruas, K. Rietdorf, A. Arredouani, L.C. Davis, E. Lloyd-Evans, H. Koegel, T.M. Funnell, A.J. Morgan, J.A. Ward, K. Watanabe, X. Cheng, G.C. Churchill, M.X. Zhu, F.M. Platt, G.M. Wessel, J. Parrington, A. Galione, Purified TPC isoforms form NAADP receptors with distinct roles for $\mathrm{Ca}(2+)$ signaling and endolysosomal trafficking, Curr. Biol. 20 (8) (2010) 703-709.

[64] J.V. Gerasimenko, A.V. Tepikin, O.H. Petersen, O.V. Gerasimenko, Calcium uptake via endocytosis with rapid release from acidifying endosomes, Curr. Biol. 8 (24) (1998) 1335-1338.

[65] M.W. Sherwood, I.A. Prior, S.G. Voronina, S.L. Barrow, J.D. Woodsmith, O.V. Gerasimenko, O.H. Petersen, A.V. Tepikin, Activation of trypsinogen in large endocytic vacuoles of pancreatic acinar cells, Proc Natl Acad Sci U S A 104 (13) (2007) 5674-5679.

[66] A.J. Morgan, L.C. Davis, S.K. Wagner, A.M. Lewis, J. Parrington, G.C. Churchill, A. Galione, Bidirectional $\mathrm{Ca}(2)(+)$ signaling occurs between the endoplasmic reticulum and acidic organelles, J. Cell Biol. 200 (6) (2013) 789-805.

[67] V. Ronco, D.M. Potenza, F. Denti, S. Vullo, G. Gagliano, M. Tognolina, G. Guerra, P. Pinton, A.A. Genazzani, L. Mapelli, D. Lim, F. Moccia, A novel Ca(2) $(+)$-mediated cross-talk between endoplasmic reticulum and acidic organelles: implications for NAADP-dependent $\mathrm{Ca}(2)(+)$ signalling, Cell Calcium 57 (2) (2015) 89-100.

[68] T. Albrecht, Y. Zhao, T.H. Nguyen, R.E. Campbell, J.D. Johnson, Fluorescent biosensors illuminate calcium levels within defined beta-cell endosome subpopulations, Cell Calcium 57 (4) (2015) 263-274.

[69] L. Sbano, M. Bonora, S. Marchi, F. Baldassari, D.L. Medina, A. Ballabio, C. Giorgi, P. Pinton, TFEB-mediated increase in peripheral lysosomes regulates store-operated calcium entry, Sci. Rep. 7 (2017) 40797.

[70] E. Lloyd-Evans, A.J. Morgan, X. He, D.A. Smith, E. Elliot-Smith, D.J. Sillence, G.C. Churchill, E.H. Schuchman, A. Galione, F.M. Platt, Niemann-Pick disease type C1 is a sphingosine storage disease that causes deregulation of lysosomal calcium, Nat. Med. 14 (11) (2008) 1247-1255.

[71] D.S. Schwarz, M.D. Blower, The endoplasmic reticulum: structure, function and response to cellular signaling, Cell. Mol. Life Sci. 73 (1) (2016) 79-94.

[72] A.E. Rusinol, Z. Cui, M.H. Chen, J.E. Vance, A unique mitochondria-associated membrane fraction from rat liver has a high capacity for lipid synthesis and contains pre-Golgi secretory proteins including nascent lipoproteins, J. Biol. Chem. 269 (44) (1994) 27494-27502.

[73] M. Fujimoto, T. Hayashi, T.P. Su, The role of cholesterol in the association of endoplasmic reticulum membranes with mitochondria, Biochem. Biophys. Res. Commun. 417 (1) (2012) 635-639.

[74] J. Stiban, L. Caputo, M. Colombini, Ceramide synthesis in the endoplasmic reticulum can permeabilize mitochondria to proapoptotic proteins, J. Lipid Res. 49 (3) (2008) 625-634.

[75] H.L. Kammoun, H. Chabanon, I. Hainault, S. Luquet, C. Magnan, T. Koike, P. Ferre, F. Foufelle, GRP78 expression inhibits insulin and ER stress-induced SREBP-1c activation and reduces hepatic steatosis in mice, J. Clin. Invest. 119 (5) (2009) 1201-1215.

[76] J. Han, R.J. Kaufman, The role of ER stress in lipid metabolism and lipotoxicity, J Lipid Res. 57 (8) (2016) 1329-1338.

[77] X. Wang, C.O. Eno, B.J. Altman, Y. Zhu, G. Zhao, K.E. Olberding, J.C. Rathmell, C. Li, ER stress modulates cellular metabolism, Biochem. J. 435 (1) (2011) 285-296.

[78] J. Kaur, J. Debnath, Autophagy at the crossroads of catabolism and anabolism, Nat. Rev. Mol. Cell Biol. 16 (8) (2015) 461-472.

[79] M. Hamasaki, N. Furuta, A. Matsuda, A. Nezu, A. Yamamoto, N. Fujita, H. Oomori, T. Noda, T. Haraguchi, Y. Hiraoka, A. Amano, T. Yoshimori, Autophagosomes form at ER-mitochondria contact sites, Nature 495 (7441) (2013) 389-393.

[80] R. Bravo, J.M. Vicencio, V. Parra, R. Troncoso, J.P. Munoz, M. Bui, C. Quiroga, A.E. Rodriguez, H.E. Verdejo, J. Ferreira, M. Iglewski, M. Chiong, T. Simmen, A. Zorzano, J.A. Hill, B.A. Rothermel, G. Szabadkai, S. Lavandero, Increased ERmitochondrial coupling promotes mitochondrial respiration and bioenergetics during early phases of ER stress, J. Cell. Sci. 124 (Pt 13) (2011) 2143-2152.

[81] R.M. Denton, Regulation of mitochondrial dehydrogenases by calcium ions, Biochim. Biophys. Acta 1787 (11) (2009) 1309-1316.

[82] C. Cardenas, R.A. Miller, I. Smith, T. Bui, J. Molgo, M. Muller, H. Vais, K.H. Cheung, J. Yang, I. Parker, C.B. Thompson, M.J. Birnbaum, K.R. Hallows, J.K. Foskett, Essential regulation of cell bioenergetics by constitutive InsP3 receptor Ca2 + transfer to mitochondria, Cell 142 (2) (2010) 270-283.

[83] G. Laurenti, D.A. Tennant, Isocitrate dehydrogenase (IDH), succinate dehydrogenase (SDH), fumarate hydratase $(\mathrm{FH})$ : three players for one phenotype in cancer? Biochem. Soc. Trans. 44 (4) (2016) 1111-1116.

[84] V. Zecchini, C. Frezza, Metabolic synthetic lethality in cancer therapy, Biochim 
Biophys Acta Bioenerg 1858 (8) (2017) 723-731.

85] D.C. Wallace, Mitochondria and cancer, Nat. Rev. Cancer 12 (10) (2012) 685-698.

[86] P.R. Territo, V.K. Mootha, S.A. French, R.S. Balaban, Ca(2+) activation of heart mitochondrial oxidative phosphorylation: role of the F(0)/F(1)-ATPase, Am. J. Physiol. Cell Physiol. 278 (2) (2000) C423-35.

[87] B. Glancy, W.T. Willis, D.J. Chess, R.S. Balaban, Effect of calcium on the oxidative phosphorylation cascade in skeletal muscle mitochondria, Biochemistry 52 (16) (2013) 2793-2809.

[88] A.W. Gao, C. Canto, R.H. Houtkooper, Mitochondrial response to nutrient availability and its role in metabolic disease, EMBO Mol. Med. 6 (5) (2014) 580-589.

[89] M. Michalak, J.M. Robert Parker, M. Opas, Ca2 + signaling and calcium binding chaperones of the endoplasmic reticulum, Cell Calcium 32 (5-6) (2002) 269-278.

[90] C. Brandt, P.J. McFie, H. Vu, P. Chumala, G.S. Katselis, S.J. Stone, Identification of calnexin as a diacylglycerol acyltransferase-2 interacting protein, PLoS One 14 (1) (2019) e0210396.

[91] J.T. Lock, K.J. Alzayady, D.I. Yule, I. Parker, All three IP3 receptor isoforms generate $\mathrm{Ca}(2+)$ puffs that display similar characteristics, Sci. Signal. 11 (561) (2018).

[92] N.B. Thillaiappan, A.P. Chavda, S.C. Tovey, D.L. Prole, C.W. Taylor, $\mathrm{Ca}(2+)$ signals initiate at immobile IP3 receptors adjacent to ER-plasma membrane junctions, Nat. Commun. 8 (1) (2017) 1505.

[93] H. Wen, W.J. Xu, X. Jin, S. Oh, C.H. Phan, J. Song, S.K. Lee, S. Park, The roles of IP3 receptor in energy metabolic pathways and reactive oxygen species homeostasis revealed by metabolomic and biochemical studies, Biochim. Biophys. Acta 1853 (11 Pt A) (2015) 2937-2944.

[94] P. Venditti, L. Di Stefano, S. Di Meo, Mitochondrial metabolism of reactive oxygen species, Mitochondrion 13 (2) (2013) 71-82.

[95] L.A. Sena, N.S. Chandel, Physiological roles of mitochondrial reactive oxygen species, Mol. Cell 48 (2) (2012) 158-167.

[96] M. Ristow, S. Schmeisser, Extending life span by increasing oxidative stress, Free Radic. Biol. Med. 51 (2) (2011) 327-336.

[97] E.D. Yoboue, A. Rimessi, T. Anelli, P. Pinton, R. Sitia, Regulation of calcium fluxes by GPX8, a Type-II transmembrane peroxidase enriched at the mitochondria-associated endoplasmic reticulum membrane, Antioxid. Redox Signal. 27 (9) (2017) $583-595$.

[98] S.Y. Gilady, M. Bui, E.M. Lynes, M.D. Benson, R. Watts, J.E. Vance, T. Simmen, Erolalpha requires oxidizing and normoxic conditions to localize to the $\mathrm{mi}$ tochondria-associated membrane (MAM), Cell Stress Chaperones 15 (5) (2010) 619-629.

[99] T. Anelli, L. Bergamelli, E. Margittai, A. Rimessi, C. Fagioli, A. Malgaroli, P. Pinton, M. Ripamonti, R. Rizzuto, R. Sitia, Erolalpha regulates $\mathrm{Ca}(2+)$ fluxes at the endoplasmic reticulum-mitochondria interface (MAM), Antioxid. Redox Signal. 16 (10) (2012) 1077-1087.

[100] B. Honrath, I. Metz, N. Bendridi, J. Rieusset, C. Culmsee, A.M. Dolga, Glucoseregulated protein 75 determines ER-mitochondrial coupling and sensitivity to oxidative stress in neuronal cells, Cell Death Discov. 3 (2017) 17076.

[101] M.G. Vander Heiden, N.S. Chandel, X.X. Li, P.T. Schumacker, M. Colombini, C.B. Thompson, Outer mitochondrial membrane permeability can regulate coupled respiration and cell survival, Proc. Natl. Acad. Sci. U. S. A. 97 (9) (2000) 4666-4671.

[102] S. Abu-Hamad, S. Sivan, V. Shoshan-Barmatz, The expression level of the voltagedependent anion channel controls life and death of the cell, Proc. Natl. Acad. Sci. U. S. A. 103 (15) (2006) 5787-5792.

[103] A.I. Tarasov, F. Semplici, M.A. Ravier, E.A. Bellomo, T.J. Pullen, P. Gilon, I. Sekler, R. Rizzuto, G.A. Rutter, The mitochondrial Ca2 + uniporter MCU is essential for glucose-induced ATP increases in pancreatic beta-cells, PLoS One 7 (7) (2012) e39722.

[104] A. Wiederkehr, G. Szanda, D. Akhmedov, C. Mataki, C.W. Heizmann, K. Schoonjans, T. Pozzan, A. Spat, C.B. Wollheim, Mitochondrial matrix calcium is an activating signal for hormone secretion, Cell Metab. 13 (5) (2011) 601-611.

[105] T. Gutierrez, V. Parra, R. Troncoso, C. Pennanen, A. Contreras-Ferrat, C. VasquezTrincado, P.E. Morales, C. Lopez-Crisosto, C. Sotomayor-Flores, M. Chiong, B.A. Rothermel, S. Lavandero, Alteration in mitochondrial $\mathrm{Ca}(2+)$ uptake disrupts insulin signaling in hypertrophic cardiomyocytes, Cell Commun. Signal 12 (2014) 68.

[106] M. Bobrich, A. Brobeil, F.C. Mooren, K. Kruger, K. Steger, C. Tag, M. Wimmer, PTPIP51 interaction with PTP1B and 14-3-3beta in adipose tissue of insulin-resistant mice, Int. J. Obes. (Lond) 35 (11) (2011) 1385-1394.

[107] M.A. Bobrich, S.A. Schwabe, A. Brobeil, M. Viard, M. Kamm, F.C. Mooren, K. Kruger, C. Tag, M. Wimmer, PTPIP51: a new interaction partner of the insulin receptor and PKA in adipose tissue, J. Obes. 2013 (2013) 476240.

[108] S.M. Han, H. El Oussini, J. Scekic-Zahirovic, J. Vibbert, P. Cottee, J.K. Prasain, H.J. Bellen, L. Dupuis, M.A. Miller, VAPB/ALS8 MSP ligands regulate striated muscle energy metabolism critical for adult survival in caenorhabditis elegans, PLoS Genet. 9 (9) (2013) e1003738.

[109] A.L. Nishimura, M. Mitne-Neto, H.C. Silva, A. Richieri-Costa, S. Middleton, D. Cascio, F. Kok, J.R. Oliveira, T. Gillingwater, J. Webb, P. Skehel, M. Zatz, A mutation in the vesicle-trafficking protein VAPB causes late-onset spinal muscular atrophy and amyotrophic lateral sclerosis, Am. J. Hum. Genet. 75 (5) (2004) 822-831.

[110] L. Aliaga, C. Lai, J. Yu, N. Chub, H. Shim, L. Sun, C. Xie, W.J. Yang, X. Lin, M.J. O'Donovan, H. Cai, Amyotrophic lateral sclerosis-related VAPB P56S mutation differentially affects the function and survival of corticospinal and spinal motor neurons, Hum. Mol. Genet. 22 (21) (2013) 4293-4305.

[111] C. Betz, D. Stracka, C. Prescianotto-Baschong, M. Frieden, N. Demaurex, M.N. Hall, Feature Article: mTOR complex 2-Akt signaling at mitochondria-associated endoplasmic reticulum membranes (MAM) regulates mitochondrial physiology, Proc. Natl. Acad. Sci. U. S. A. 110 (31) (2013) 12526-12534.

[112] Z. Zhang, H. Liu, J. Liu, Akt activation: a potential strategy to ameliorate insulin resistance, Diabetes Res. Clin. Pract. (2017).

[113] D. Sebastian, M.I. Hernandez-Alvarez, J. Segales, E. Sorianello, J.P. Munoz, D. Sala, A. Waget, M. Liesa, J.C. Paz, P. Gopalacharyulu, M. Oresic, S. Pich, R. Burcelin, M. Palacin, A. Zorzano, Mitofusin 2 (Mfn2) links mitochondrial and endoplasmic reticulum function with insulin signaling and is essential for normal glucose homeostasis, Proc. Natl. Acad. Sci. U. S. A. 109 (14) (2012) 5523-5528.

[114] D. Bach, S. Pich, F.X. Soriano, N. Vega, B. Baumgartner, J. Oriola, J.R. Daugaard, J. Lloberas, M. Camps, J.R. Zierath, R. Rabasa-Lhoret, H. Wallberg-Henriksson, M. Laville, M. Palacin, H. Vidal, F. Rivera, M. Brand, A. Zorzano, Mitofusin-2 determines mitochondrial network architecture and mitochondrial metabolism. A novel regulatory mechanism altered in obesity, J. Biol. Chem. 278 (19) (2003) 17190-17197.

[115] S. Pich, D. Bach, P. Briones, M. Liesa, M. Camps, X. Testar, M. Palacin, A. Zorzano, The Charcot-Marie-Tooth type 2A gene product, Mfn2, up-regulates fuel oxidation through expression of OXPHOS system, Hum. Mol. Genet. 14 (11) (2005) $1405-1415$.

[116] K.H. Chen, A. Dasgupta, J. Ding, F.E. Indig, P. Ghosh, D.L. Longo, Role of mitofusin 2 (Mfn2) in controlling cellular proliferation, FASEB J. 28 (1) (2014) 382-394.

[117] E. Schrepfer, L. Scorrano, Mitofusins, from mitochondria to metabolism, Mol. Cell 61 (5) (2016) 683-694.

[118] D. Loiseau, A. Chevrollier, C. Verny, V. Guillet, N. Gueguen, M.A. Pou de Crescenzo, M. Ferre, M.C. Malinge, A. Guichet, G. Nicolas, P. Amati-Bonneau, Y. Malthiery, D. Bonneau, P. Reynier, Mitochondrial coupling defect in CharcotMarie-Tooth type 2A disease, Ann. Neurol. 61 (4) (2007) 315-323.

[119] C.L. Chang, Y.J. Chen, J. Liou, ER-plasma membrane junctions: Why and how do we study them? Biochim. Biophys. Acta Mol. Cell Res. 1864 (9) (2017) 1494-1506.

[120] H. Pichler, B. Gaigg, C. Hrastnik, G. Achleitner, S.D. Kohlwein, G. Zellnig, A. Perktold, G. Daum, A subfraction of the yeast endoplasmic reticulum associates with the plasma membrane and has a high capacity to synthesize lipids, Eur. J. Biochem. 268 (8) (2001) 2351-2361.

[121] J.A. Lees, M. Messa, E.W. Sun, H. Wheeler, F. Torta, M.R. Wenk, P. De Camilli, K.M. Reinisch, Lipid transport by TMEM24 at ER-plasma membrane contacts regulates pulsatile insulin secretion, Science 355 (6326) (2017).

[122] P.J. Bartlett, L.D. Gaspers, N. Pierobon, A.P. Thomas, Calcium-dependent regulation of glucose homeostasis in the liver, Cell Calcium 55 (6) (2014) 306-316.

[123] R. Ghai, X. Du, H. Wang, J. Dong, C. Ferguson, A.J. Brown, R.G. Parton, J.W. Wu, H. Yang, ORP5 and ORP8 bind phosphatidylinositol-4, 5-biphosphate (PtdIns $(4,5)$ P 2) and regulate its level at the plasma membrane, Nat. Commun. 8 (1) (2017) 757.

[124] I. Pulli, T. Lassila, G. Pan, D. Yan, V.M. Olkkonen, K. Tornquist, Oxysterol-binding protein related-proteins (ORPs) 5 and 8 regulate calcium signaling at specific cell compartments, Cell Calcium 72 (2018) 62-69.

[125] A.C. Nascimbeni, F. Giordano, N. Dupont, D. Grasso, M. Vaccaro, P. Codogno, E. Morel, ER-plasma membrane contact sites contribute to autophagosome biogenesis by regulation of local PI3P synthesis, EMBO J. 36 (14) (2017) 2018-2033.

[126] G.G. Hesketh, L. Wartosch, L.J. Davis, N.A. Bright, J.P. Luzio, The lysosome and intracellular signalling, Prog. Mol. Subcell. Biol. 57 (2018) 151-180.

[127] C.J. Penny, B.S. Kilpatrick, E.R. Eden, S. Patel, Coupling acidic organelles with the ER through $\mathrm{Ca}(2)(+)$ microdomains at membrane contact sites, Cell Calcium 58 (4) (2015) 387-396.

[128] D.L. Medina, S. Di Paola, I. Peluso, A. Armani, D. De Stefani, R. Venditti, S. Montefusco, A. Scotto-Rosato, C. Prezioso, A. Forrester, C. Settembre, W. Wang, Q. Gao, H. Xu, M. Sandri, R. Rizzuto, M.A. De Matteis, A. Ballabio, Lysosomal calcium signalling regulates autophagy through calcineurin and TFEB, Nat. Cell Biol. 17 (3) (2015) 288-299.

[129] A.G. Garrity, W. Wang, C.M. Collier, S.A. Levey, Q. Gao, H. Xu, The endoplasmic reticulum, not the $\mathrm{pH}$ gradient, drives calcium refilling of lysosomes, Elife 5 (2016).

[130] E.R. Eden, I.J. White, A. Tsapara, C.E. Futter, Membrane contacts between endosomes and ER provide sites for PTP1B-epidermal growth factor receptor interaction, Nat. Cell Biol. 12 (3) (2010) 267-272.

[131] H.C. Lee, Cyclic ADP-ribose and nicotinic acid adenine dinucleotide phosphate (NAADP) as messengers for calcium mobilization, J. Biol. Chem. 287 (38) (2012) 31633-31640.

[132] S.J. Pitt, T.M. Funnell, M. Sitsapesan, E. Venturi, K. Rietdorf, M. Ruas, A. Ganesan, R. Gosain, G.C. Churchill, M.X. Zhu, J. Parrington, A. Galione, R. Sitsapesan, TPC2 is a novel NAADP-sensitive Ca2 + release channel, operating as a dual sensor of luminal pH and Ca2 +, J. Biol. Chem. 285 (45) (2010) 35039-35046.

[133] B.E. Steinberg, K.K. Huynh, A. Brodovitch, S. Jabs, T. Stauber, T.J. Jentsch, S. Grinstein, A cation counterflux supports lysosomal acidification, J. Cell Biol. 189 (7) (2010) 1171-1186.

[134] R.A. Capel, E.L. Bolton, W.K. Lin, D. Aston, Y. Wang, W. Liu, X. Wang, R.A. Burton, D. Bloor-Young, K.T. Shade, M. Ruas, J. Parrington, G.C. Churchill, M. Lei, A. Galione, D.A. Terrar, Two-pore channels (TPC2s) and nicotinic acid adenine dinucleotide phosphate (NAADP) at lysosomal-sarcoplasmic reticular junctions contribute to acute and chronic beta-adrenoceptor signaling in the heart, J. Biol. Chem. 290 (50) (2015) 30087-30098.

[135] G. Morciano, S. Marchi, C. Morganti, L. Sbano, M. Bittremieux, M. Kerkhofs, M. Corricelli, A. Danese, A. Karkucinska-Wieckowska, M.R. Wieckowski, G. Bultynck, C. Giorgi, P. Pinton, Role of mitochondria-associated ER membranes in calcium regulation in cancer-specific settings, Neoplasia 20 (5) (2018) 510-523. 
[136] N. Prevarskaya, H. Ouadid-Ahidouch, R. Skryma, Y. Shuba, Remodelling of Ca2 + transport in cancer: how it contributes to cancer hallmarks? Philos. Trans. R. Soc. Lond. B Biol. Sci. 369 (1638) (2014) 20130097.

[137] D. Hanahan, R.A. Weinberg, The hallmarks of cancer, Cell 100 (1) (2000) 57-70.

[138] C. Cardenas, P. Pinton, G. Bultynck, Editorial: inter-organelle calcium communication in cancer, Front. Oncol. 8 (2018) 14.

[139] A.A. Rowland, G.K. Voeltz, Endoplasmic reticulum-mitochondria contacts: function of the junction, Nat. Rev. Mol. Cell Biol. 13 (10) (2012) 607-625.

[140] M. Bonora, C. Morganti, G. Morciano, G. Pedriali, M. Lebiedzinska-Arciszewska, G. Aquila, C. Giorgi, P. Rizzo, G. Campo, R. Ferrari, G. Kroemer, M.R. Wieckowski, L. Galluzzi, P. Pinton, Mitochondrial permeability transition involves dissociation of F1FO ATP synthase dimers and C-ring conformation, EMBO Rep. 18 (7) (2017) 1077-1089.

[141] M. Bittremieux, J.B. Parys, P. Pinton, G. Bultynck, ER functions of oncogenes and tumor suppressors: modulators of intracellular $\mathrm{Ca}(2+)$ signaling, Biochim. Biophys. Acta 1863 (6 Pt B) (2016) 1364-1378.

[142] S. Krajewski, S. Tanaka, S. Takayama, M.J. Schibler, W. Fenton, J.C. Reed, Investigation of the subcellular distribution of the bcl-2 oncoprotein: residence in the nuclear envelope, endoplasmic reticulum, and outer mitochondrial membranes, Cancer Res. 53 (19) (1993) 4701-4714.

[143] Y.P. Rong, G. Bultynck, A.S. Aromolaran, F. Zhong, J.B. Parys, H. De Smedt, G.A. Mignery, H.L. Roderick, M.D. Bootman, C.W. Distelhorst, The BH4 domain of Bcl-2 inhibits ER calcium release and apoptosis by binding the regulatory and coupling domain of the IP3 receptor, Proc. Natl. Acad. Sci. U. S. A. 106 (34) (2009) 14397-14402.

[144] G. Packham, Mutation of BCL-2 family proteins in Cancer, Apoptosis 3 (2) (1998) 75-82.

[145] T. Vervliet, E. Clerix, B. Seitaj, H. Ivanova, G. Monaco, G. Bultynck, Modulation of $\mathrm{Ca}(2+)$ signaling by anti-apoptotic B-Cell lymphoma 2 proteins at the endoplasmic reticulum-mitochondrial interface, Front. Oncol. 7 (2017) 75.

[146] M. Adachi, J. Cossman, D. Longo, C.M. Croce, Y. Tsujimoto, Variant translocation of the bcl-2 gene to immunoglobulin lambda light chain gene in chronic lymphocytic leukemia, Proc. Natl. Acad. Sci. U. S. A. 86 (8) (1989) 2771-2774.

[147] A.C. Aisenberg, B.M. Wilkes, J.O. Jacobson, The bcl-2 gene is rearranged in many diffuse B-cell lymphomas, Blood 71 (4) (1988) 969-972.

[148] J.C. Daniel, W.R. Smythe, The role of Bcl-2 family members in non-small cell lung cancer, Semin. Thorac. Cardiovasc. Surg. 16 (1) (2004) 19-27.

[149] H. Akl, R.M. La Rovere, A. Janssens, P. Vandenberghe, J.B. Parys, G. Bultynck, HA14-1 potentiates apoptosis in B-cell cancer cells sensitive to a peptide disrupting IP 3 receptor / Bcl-2 complexes, Int. J. Dev. Biol. 59 (7-9) (2015) 391-398.

[150] E.F. Greenberg, K.S. McColl, F. Zhong, G. Wildey, A. Dowlati, C.W. Distelhorst, Synergistic killing of human small cell lung cancer cells by the Bcl-2-inositol 1,4,5trisphosphate receptor disruptor BIRD-2 and the BH3-mimetic ABT-263, Cell Death Dis. 6 (2015) e2034.

[151] H. Akl, G. Monaco, R. La Rovere, K. Welkenhuyzen, S. Kiviluoto, T. Vervliet, J. Molgo, C.W. Distelhorst, L. Missiaen, K. Mikoshiba, J.B. Parys, H. De Smedt, G. Bultynck, IP3R2 levels dictate the apoptotic sensitivity of diffuse large B-cell lymphoma cells to an IP3R-derived peptide targeting the BH4 domain of Bcl-2, Cell Death Dis. 4 (2013) e632.

[152] A.R. Lavik, F. Zhong, M.J. Chang, E. Greenberg, Y. Choudhary, M.R. Smith, K.S. McColl, J. Pink, F.J. Reu, S. Matsuyama, C.W. Distelhorst, A synthetic peptide targeting the $\mathrm{BH} 4$ domain of $\mathrm{Bcl}-2$ induces apoptosis in multiple myeloma and follicular lymphoma cells alone or in combination with agents targeting the BH3binding pocket of Bcl-2, Oncotarget 6 (29) (2015) 27388-27402.

[153] Y. Tsujimoto, S. Shimizu, VDAC regulation by the Bcl-2 family of proteins, Cell Death Differ. 7 (12) (2000) 1174-1181.

[154] J. Michels, O. Kepp, L. Senovilla, D. Lissa, M. Castedo, G. Kroemer, L. Galluzzi, Functions of BCL-X 1 at the interface between cell death and metabolism, Int. J. Cell Biol. 2013 (2013) 705294.

[155] D. Trisciuoglio, M.G. Tupone, M. Desideri, M. Di Martile, C. Gabellini, S. Buglioni, M. Pallocca, G. Alessandrini, S. D’Aguanno, D. Del Bufalo, BCL-XL overexpression promotes tumor progression-associated properties, Cell Death Dis. 8 (12) (2017) 3216.

[156] K. Zhang, K. Jiao, Z. Xing, L. Zhang, J. Yang, X. Xie, L. Yang, Bcl-xL overexpression and its association with the progress of tongue carcinoma, Int. J. Clin. Exp. Pathol. 7 (11) (2014) 7360-7377.

[157] S. Yoshimine, E. Kikuchi, T. Kosaka, S. Mikami, A. Miyajima, Y. Okada, M. Oya, Prognostic significance of Bcl-xL expression and efficacy of Bcl-xL targeting therapy in urothelial carcinoma, Br. J. Cancer 108 (11) (2013) 2312-2320.

[158] A.L. Scherr, G. Gdynia, M. Salou, P. Radhakrishnan, K. Duglova, A. Heller, S. Keim, N. Kautz, A. Jassowicz, C. Elssner, Y.W. He, D. Jaeger, M. Heikenwalder, M. Schneider, A. Weber, W. Roth, H. Schulze-Bergkamen, B.C. Koehler, Bcl-xL is an oncogenic driver in colorectal cancer, Cell Death Dis. 7 (8) (2016) e2342.

[159] C. White, C. Li, J. Yang, N.B. Petrenko, M. Madesh, C.B. Thompson, J.K. Foskett, The endoplasmic reticulum gateway to apoptosis by Bcl-X(L) modulation of the InsP3R, Nat. Cell Biol. 7 (10) (2005) 1021-1028.

[160] C.M. Adams, S. Clark-Garvey, P. Porcu, C.M. Eischen, Targeting the Bcl-2 family in B cell lymphoma, Front. Oncol. 8 (2018) 636.

[161] J.D. Leverson, D.C. Phillips, M.J. Mitten, E.R. Boghaert, D. Diaz, S.K. Tahir, L.D. Belmont, P. Nimmer, Y. Xiao, X.M. Ma, K.N. Lowes, P. Kovar, J. Chen, S. Jin, M. Smith, J. Xue, H. Zhang, A. Oleksijew, T.J. Magoc, K.S. Vaidya, D.H. Albert, J.M. Tarrant, N. La, L. Wang, Z.F. Tao, M.D. Wendt, D. Sampath, S.H. Rosenberg, C. Tse, D.C. Huang, W.J. Fairbrother, S.W. Elmore, A.J. Souers, Exploiting selective BCL-2 family inhibitors to dissect cell survival dependencies and define improved strategies for cancer therapy, Sci. Transl. Med. 7 (279) (2015) 279 ra40.

[162] P.J. Sung, F.D. Tsai, H. Vais, H. Court, J. Yang, N. Fehrenbacher, J.K. Foskett,
M.R. Philips, Phosphorylated K-Ras limits cell survival by blocking Bcl-xL sensitization of inositol trisphosphate receptors, Proc. Natl. Acad. Sci. U. S. A. 110 (51) (2013) 20593-20598.

[163] T.G. Bivona, S.E. Quatela, B.O. Bodemann, I.M. Ahearn, M.J. Soskis, A. Mor, J. Miura, H.H. Wiener, L. Wright, S.G. Saba, D. Yim, A. Fein, I. Perez de Castro, C. Li, C.B. Thompson, A.D. Cox, M.R. Philips, PKC regulates a farnesyl-electrostatic switch on K-Ras that promotes its association with Bcl-XL on mitochondria and induces apoptosis, Mol. Cell 21 (4) (2006) 481-493.

[164] C. Pierro, S.J. Cook, T.C. Foets, M.D. Bootman, H.L. Roderick, Oncogenic K-Ras suppresses IP(3)-dependent $\mathrm{Ca}(2)(+)$ release through remodelling of the isoform composition of IP(3)Rs and ER luminal $\mathrm{Ca}(2)(+)$ levels in colorectal cancer cell lines, J. Cell. Sci. 127 (Pt 7) (2014) 1607-1619.

[165] Y. Hu, W. Lu, G. Chen, P. Wang, Z. Chen, Y. Zhou, M. Ogasawara, D. Trachootham, L. Feng, H. Pelicano, P.J. Chiao, M.J. Keating, G. Garcia-Manero, P. Huang, K-ras (G12V) transformation leads to mitochondrial dysfunction and a metabolic switch from oxidative phosphorylation to glycolysis, Cell Res. 22 (2) (2012) 399-412.

[166] S. Marchi, M. Marinello, A. Bononi, M. Bonora, C. Giorgi, A. Rimessi, P. Pinton, Selective modulation of subtype III IP(3)R by Akt regulates ER Ca(2)(+) release and apoptosis, Cell Death Dis. 3 (2012) e304.

[167] S. Marchi, A. Rimessi, C. Giorgi, C. Baldini, L. Ferroni, R. Rizzuto, P. Pinton, Akt kinase reducing endoplasmic reticulum $\mathrm{Ca} 2+$ release protects cells from $\mathrm{Ca} 2+$ dependent apoptotic stimuli, Biochem. Biophys. Res. Commun. 375 (4) (2008) 501-505.

[168] P.S. Mundi, J. Sachdev, C. McCourt, K. Kalinsky, AKT in cancer: new molecular insights and advances in drug development, Br. J. Clin. Pharmacol. 82 (4) (2016) 943-956.

[169] S. Marchi, M. Corricelli, A. Branchini, V.A.M. Vitto, S. Missiroli, G. Morciano, M. Perrone, M. Ferrarese, C. Giorgi, M. Pinotti, L. Galluzzi, G. Kroemer, P. Pinton, Akt-mediated phosphorylation of MICU1 regulates mitochondrial $\mathrm{Ca}(2+)$ levels and tumor growth, EMBO J. 38 (2) (2019).

[170] J. Wang, X. Xiao, Y. Zhang, D. Shi, W. Chen, L. Fu, L. Liu, F. Xie, T. Kang, W. Huang, W. Deng, Simultaneous modulation of COX-2, p300, Akt, and Apaf-1 signaling by melatonin to inhibit proliferation and induce apoptosis in breast cancer cells, J. Pineal Res. 53 (1) (2012) 77-90.

[171] Y. Li, S. Li, Y. Zhou, X. Meng, J.J. Zhang, D.P. Xu, H.B. Li, Melatonin for the prevention and treatment of cancer, Oncotarget 8 (24) (2017) 39896-39921.

[172] A. Tarocco, N. Caroccia, G. Morciano, M.R. Wieckowski, G. Ancora, G. Garani, P. Pinton, Melatonin as a master regulator of cell death and inflammation: molecular mechanisms and clinical implications for newborn care, Cell Death Dis. 10 (4) (2019) 317

[173] C. Eng, PTEN: one gene, many syndromes, Hum. Mutat. 22 (3) (2003) 183-198.

[174] M. Osaki, M. Oshimura, H. Ito, PI3K-Akt pathway: its functions and alterations in human cancer, Apoptosis 9 (6) (2004) 667-676.

[175] A. Bononi, M. Bonora, S. Marchi, S. Missiroli, F. Poletti, C. Giorgi, P.P. Pandolfi, P. Pinton, Identification of PTEN at the ER and MAMs and its regulation of $\mathrm{Ca}(2+)$ signaling and apoptosis in a protein phosphatase-dependent manner, Cell Death Differ. 20 (12) (2013) 1631-1643.

[176] S. Kuchay, C. Giorgi, D. Simoneschi, J. Pagan, S. Missiroli, A. Saraf, L. Florens, M.P. Washburn, A. Collazo-Lorduy, M. Castillo-Martin, C. Cordon-Cardo, S.M. Sebti, P. Pinton, M. Pagano, PTEN counteracts FBXL2 to promote IP3R3- and $\mathrm{Ca}(2+)$-mediated apoptosis limiting tumour growth, Nature 546 (7659) (2017) $554-558$.

[177] C. Giorgi, K. Ito, H.K. Lin, C. Santangelo, M.R. Wieckowski, M. Lebiedzinska, A. Bononi, M. Bonora, J. Duszynski, R. Bernardi, R. Rizzuto, C. Tacchetti, P. Pinton, P.P. Pandolfi, PML regulates apoptosis at endoplasmic reticulum by modulating calcium release, Science 330 (6008) (2010) 1247-1251.

[178] S. Missiroli, M. Bonora, S. Patergnani, F. Poletti, M. Perrone, R. Gafa, E. Magri, A. Raimondi, G. Lanza, C. Tacchetti, G. Kroemer, P.P. Pandolfi, P. Pinton, C. Giorgi, PML at mitochondria-associated membranes is critical for the repression of autophagy and Cancer development, Cell Rep. 16 (9) (2016) 2415-2427.

[179] J.T. Zilfou, S.W. Lowe, Tumor suppressive functions of p53, Cold Spring Harb. Perspect. Biol. 1 (5) (2009) a001883.

[180] C. Giorgi, M. Bonora, G. Sorrentino, S. Missiroli, F. Poletti, J.M. Suski, F. Galindo Ramirez, R. Rizzuto, F. Di Virgilio, E. Zito, P.P. Pandolfi, M.R. Wieckowski, F. Mammano, G. Del Sal, P. Pinton, p53 at the endoplasmic reticulum regulates apoptosis in a Ca2+-dependent manner, Proc. Natl. Acad. Sci. U. S. A. 112 (6) (2015) 1779-1784.

[181] R. Wadhwa, T. Yaguchi, M.K. Hasan, Y. Mitsui, R.R. Reddel, S.C. Kaul, Hsp70 family member, mot-2/mthsp70/GRP75, binds to the cytoplasmic sequestration domain of the p53 protein, Exp. Cell Res. 274 (2) (2002) 246-253.

[182] R. Wadhwa, S. Takano, M. Robert, A. Yoshida, H. Nomura, R.R. Reddel, Y. Mitsui, S.C. Kaul, Inactivation of tumor suppressor p53 by mot-2, a hsp70 family member, J. Biol. Chem. 273 (45) (1998) 29586-29591.

[183] X. Yi, J.M. Luk, N.P. Lee, J. Peng, X. Leng, X.Y. Guan, G.K. Lau, L. Beretta, S.T. Fan, Association of mortalin (HSPA9) with liver cancer metastasis and prediction for early tumor recurrence, Mol. Cell Proteomics 7 (2) (2008) 315-325.

[184] L. Yang, H. Li, Y. Jiang, J. Zuo, W. Liu, Inhibition of mortalin expression reverses cisplatin resistance and attenuates growth of ovarian cancer cells, Cancer Lett. 336 (1) (2013) 213-221.

[185] C.O. Yun, P. Bhargava, Y. Na, J.S. Lee, J. Ryu, S.C. Kaul, R. Wadhwa, Relevance of mortalin to cancer cell stemness and cancer therapy, Sci. Rep. 7 (2017) 42016.

[186] V. Shoshan-Barmatz, D. Mizrachi, VDAC1: from structure to cancer therapy, Front Oncol. 2 (2012) 164

[187] T. Arif, L. Vasilkovsky, Y. Refaely, A. Konson, V. Shoshan-Barmatz, Silencing VDAC1 expression by siRNA inhibits Cancer cell proliferation and tumor growth in vivo, Mol, Ther. Nucleic Acids 3 (2014) e159. 
[188] V. Shoshan-Barmatz, Y. Krelin, A. Shteinfer-Kuzmine, T. Arif, Voltage-dependent anion channel 1 As an emerging drug target for novel anti-cancer therapeutics, Front. Oncol. 7 (2017) 154.

[189] A. Vultur, C.S. Gibhardt, H. Stanisz, I. Bogeski, The role of the mitochondrial calcium uniporter (MCU) complex in cancer, Pflugers Arch. (2018).

[190] S. Marchi, L. Lupini, S. Patergnani, A. Rimessi, S. Missiroli, M. Bonora, A. Bononi, F. Corra, C. Giorgi, E. De Marchi, F. Poletti, R. Gafa, G. Lanza, M. Negrini, R. Rizzuto, P. Pinton, Downregulation of the mitochondrial calcium uniporter by cancer-related miR-25, Curr. Biol. 23 (1) (2013) 58-63.

[191] C. Yu, Y. Wang, J. Peng, Q. Shen, M. Chen, W. Tang, X. Li, C. Cai, B. Wang, S. Cai, X. Meng, F. Zou, Mitochondrial calcium uniporter as a target of microRNA-340 and promoter of metastasis via enhancing the Warburg effect, Oncotarget 8 (48) (2017) 83831-83844.

[192] D.M. Arduino, J. Wettmarshausen, H. Vais, P. Navas-Navarro, Y. Cheng, A. Leimpek, Z. Ma, A. Delrio-Lorenzo, A. Giordano, C. Garcia-Perez, G. Medard, B. Kuster, J. Garcia-Sancho, D. Mokranjac, J.K. Foskett, M.T. Alonso, F. Perocchi, Systematic identification of MCU modulators by orthogonal interspecies chemical screening, Mol. Cell 67 (4) (2017) 711-723 e7.

[193] N. Kon, M. Murakoshi, A. Isobe, K. Kagechika, N. Miyoshi, T. Nagayama, DS16570511 is a small-molecule inhibitor of the mitochondrial calcium uniporter, Cell Death Discov. 3 (2017) 17045.

[194] J.J. Woods, N. Nemani, S. Shanmughapriya, A. Kumar, M. Zhang, S.R. Nathan, M. Thomas, E. Carvalho, K. Ramachandran, S. Srikantan, P.B. Stathopulos, J.J. Wilson, M. Madesh, A selective and cell-permeable mitochondrial calcium uniporter (MCU) inhibitor preserves mitochondrial bioenergetics after Hypoxia/ Reoxygenation injury, ACS Cent. Sci. 5 (1) (2019) 153-166.

[195] A. Rimessi, S. Marchi, C. Fotino, A. Romagnoli, K. Huebner, C.M. Croce, P. Pinton, R. Rizzuto, Intramitochondrial calcium regulation by the FHIT gene product sensitizes to apoptosis, Proc. Natl. Acad. Sci. U. S. A. 106 (31) (2009) 12753-12758.

[196] V. Jabs, K. Edlund, H. Konig, M. Grinberg, K. Madjar, J. Rahnenfuhrer, S. Ekman, M. Bergkvist, L. Holmberg, K. Ickstadt, J. Botling, J.G. Hengstler, P. Micke, Integrative analysis of genome-wide gene copy number changes and gene expression in non-small cell lung cancer, PLoS One 12 (11) (2017) e0187246.

[197] R. Filadi, D. Pendin, P. Pizzo, Mitofusin 2: from functions to disease, Cell Death Dis. 9 (3) (2018) 330.

[198] K. Xu, G. Chen, X. Li, X. Wu, Z. Chang, J. Xu, Y. Zhu, P. Yin, X. Liang, L. Dong, MFN2 suppresses cancer progression through inhibition of mTORC2/Akt signaling, Sci. Rep. 7 (2017) 41718.

[199] J. Rehman, H.J. Zhang, P.T. Toth, Y. Zhang, G. Marsboom, Z. Hong, R. Salgia, A.N. Husain, C. Wietholt, S.L. Archer, Inhibition of mitochondrial fission prevents cell cycle progression in lung cancer, FASEB J. 26 (5) (2012) 2175-2186.

[200] W. Wang, J. Lu, F. Zhu, J. Wei, C. Jia, Y. Zhang, L. Zhou, H. Xie, S. Zheng, Proapoptotic and anti-proliferative effects of mitofusin-2 via Bax signaling in hepatocellular carcinoma cells, Med. Oncol. 29 (1) (2012) 70-76.

[201] X. Cheng, D. Zhou, J. Wei, J. Lin, Cell-cycle arrest at G2/M and proliferation in hibition by adenovirus-expressed mitofusin- 2 gene in human colorectal cancer cell lines, Neoplasma 60 (6) (2013) 620-626.

[202] K. Chin, S. DeVries, J. Fridlyand, P.T. Spellman, R. Roydasgupta, W.L. Kuo, A. Lapuk, R.M. Neve, Z. Qian, T. Ryder, F. Chen, H. Feiler, T. Tokuyasu, C. Kingsley, S. Dairkee, Z. Meng, K. Chew, D. Pinkel, A. Jain, B.M. Ljung, L. Esserman, D.G. Albertson, F.M. Waldman, J.W. Gray, Genomic and transcriptional aberrations linked to breast cancer pathophysiologies, Cancer Cell 10 (6) (2006) 529-541.

[203] M. Rao, W. Song, A. Jiang, Y. Shyr, S. Lev, D. Greenstein, D. Brantley-Sieders, J. Chen, VAMP-associated protein B (VAPB) promotes breast tumor growth by modulation of Akt activity, PLoS One 7 (10) (2012) e46281.

[204] P. Koch, A. Stenzinger, M. Viard, D. Marker, P. Mayser, M. Nilles, D. Schreiner, K. Steger, M. Wimmer, The novel protein PTPIP51 is expressed in human keratinocyte carcinomas and their surrounding stroma, J. Cell. Mol. Med. 12 (5B) (2008) 2083-2095.

[205] M.K. Petri, A. Brobeil, J. Planz, A. Brauninger, S. Gattenlohner, U. Nestler, A. Stenzinger, A. Paradowska, M. Wimmer, PTPIP51 levels in glioblastoma cells depend on inhibition of the EGF-receptor, J. Neurooncol. 123 (1) (2015) 15-25.

[206] P. Koch, M. Petri, A. Paradowska, A. Stenzinger, K. Sturm, K. Steger, M. Wimmer, PTPIP51 mRNA and protein expression in tissue microarrays and promoter methylation of benign prostate hyperplasia and prostate carcinoma, Prostate 69 (16) (2009) 1751-1762.

[207] A. Stenzinger, D. Schreiner, P. Koch, H.W. Hofer, M. Wimmer, Cell and molecular biology of the novel protein tyrosine-phosphatase-interacting protein 51, Int. Rev. Cell Mol. Biol. 275 (2009) 183-246.

[208] X. Du, N. Turner, H. Yang, The role of oxysterol-binding protein and its related proteins in cancer, Semin. Cell Dev. Biol. 81 (2018) 149-153.

[209] S. Ishikawa, Y. Nagai, T. Masuda, Y. Koga, T. Nakamura, Y. Imamura, H. Takamori, M. Hirota, A. Funakosi, M. Fukushima, H. Baba, The role of oxysterol binding protein-related protein 5 in pancreatic cancer, Cancer Sci. 101 (4) (2010) 898-905.

[210] W. Zhong, S. Qin, B. Zhu, M. Pu, F. Liu, L. Wang, G. Ye, Q. Yi, D. Yan, Oxysterolbinding protein-related protein 8 (ORP8) increases sensitivity of hepatocellular carcinoma cells to Fas-mediated apoptosis, J. Biol. Chem. 290 (14) (2015) 8876-8887.

[211] R. Hodeify, F. Yu, R. Courjaret, N. Nader, M. Dib, L. Sun, E. Adap, S. Hubrack, K. Machaca, Regulation and Role of Store-Operated $\mathrm{Ca}(2+)$ Entry in Cellular Proliferation, (2018), pp. 215-240.

[212] S. Sabbioni, G. Barbanti-Brodano, C.M. Croce, M. Negrini, GOK: a gene at 11p15 involved in rhabdomyosarcoma and rhabdoid tumor development, Cancer Res. 57
(20) (1997) 4493-4497.

[213] J. Xie, H. Pan, J. Yao, Y. Zhou, W. Han, SOCE and cancer: recent progress and new perspectives, Int. J. Cancer 138 (9) (2016) 2067-2077.

[214] F. Vanden Abeele, Y. Shuba, M. Roudbaraki, L. Lemonnier, K. Vanoverberghe, P. Mariot, R. Skryma, N. Prevarskaya, Store-operated Ca2 + channels in prostate cancer epithelial cells: function, regulation, and role in carcinogenesis, Cell Calcium 33 (5-6) (2003) 357-373.

[215] S. Yang, J.J. Zhang, X.Y. Huang, Orai1 and STIM1 are critical for breast tumor cell migration and metastasis, Cancer Cell 15 (2) (2009) 124-134.

[216] J.H. Kim, S. Lkhagvadorj, M.R. Lee, K.H. Hwang, H.C. Chung, J.H. Jung, S.K. Cha, M. Eom, Orai1 and STIM1 are critical for cell migration and proliferation of clear cell renal cell carcinoma, Biochem. Biophys. Res. Commun. 448 (1) (2014) 76-82.

[217] J.Y. Wang, J. Sun, M.Y. Huang, Y.S. Wang, M.F. Hou, Y. Sun, H. He, N. Krishna, S.J. Chiu, S. Lin, S. Yang, W.C. Chang, STIM1 overexpression promotes colorectal cancer progression, cell motility and COX-2 expression, Oncogene 34 (33) (2015) 4358-4367.

[218] F.C. Tsai, A. Seki, H.W. Yang, A. Hayer, S. Carrasco, S. Malmersjo, T. Meyer, A polarized $\mathrm{Ca} 2+$, diacylglycerol and STIM1 signalling system regulates directed cell migration, Nat. Cell Biol. 16 (2) (2014) 133-144.

[219] Y.F. Chen, W.T. Chiu, Y.T. Chen, P.Y. Lin, H.J. Huang, C.Y. Chou, H.C. Chang, M.J. Tang, M.R. Shen, Calcium store sensor stromal-interaction molecule 1-dependent signaling plays an important role in cervical cancer growth, migration, and angiogenesis, Proc. Natl. Acad. Sci. U. S. A. 108 (37) (2011) 15225-15230.

[220] M. Feng, D.M. Grice, H.M. Faddy, N. Nguyen, S. Leitch, Y. Wang, S. Muend, P.A. Kenny, S. Sukumar, S.J. Roberts-Thomson, G.R. Monteith, R. Rao, Store-independent activation of Orai1 by SPCA2 in mammary tumors, Cell 143 (1) (2010) 84-98.

[221] M. Umemura, E. Baljinnyam, S. Feske, M.S. De Lorenzo, L.H. Xie, X. Feng, K. Oda, A. Makino, T. Fujita, U. Yokoyama, M. Iwatsubo, S. Chen, J.S. Goydos, Y. Ishikawa, K. Iwatsubo, Store-operated Ca2 + entry (SOCE) regulates melanoma proliferation and cell migration, PLoS One 9 (2) (2014) e89292.

[222] J.A. Engelman, X.L. Zhang, F. Galbiati, M.P. Lisanti, Chromosomal localization, genomic organization, and developmental expression of the murine caveolin gene family (Cav-1, -2, and -3). Cav-1 and Cav-2 genes map to a known tumor suppressor locus (6-A2/7q31), FEBS Lett. 429 (3) (1998) 330-336.

[223] S. Fan, J. Meng, L. Zhang, X. Zhang, C. Liang, CAV1 polymorphisms rs1049334, rs1049337, rs7804372 might be the potential risk in tumorigenicity of urinary cancer: a systematic review and meta-analysis, Pathol. Res. Pract. 215 (1) (2019) $151-158$.

[224] Y. Wang, Y. Song, X. Che, L. Zhang, Q. Wang, X. Zhang, J. Qu, Z. Li, L. Xu, Y. Zhang, Y. Fan, K. Hou, Y. Liu, X. Qu, Caveolin1 enhances RANKLinduced gastric cancer cell migration, Oncol. Rep. 40 (3) (2018) 1287-1296.

[225] Y. Fourbon, M. Gueguinou, R. Felix, B. Constantin, A. Uguen, G. Fromont, L. Lajoie, C. Magaud, T. Lecomte, E. Chamorey, A. Chatelier, O. Mignen, M. PotierCartereau, A. Chantome, P. Bois, C. Vandier, $\mathrm{Ca}(2+)$ protein alpha 1D of CaV1.3 regulates intracellular calcium concentration and migration of colon cancer cells through a non-canonical activity, Sci. Rep. 7 (1) (2017) 14199.

[226] W. Zhou, L. He, Y. Dai, Y. Zhang, J. Wang, B. Liu, MicroRNA-124 inhibits cell proliferation, invasion and migration by targeting CAV1 in bladder cancer, Exp. Ther. Med. 16 (4) (2018) 2811-2820.

[227] T. Godfraind, Discovery and development of calcium channel blockers, Front. Pharmacol. 8 (2017) 286.

[228] K.E. Jarman, P.A. Moretti, J.R. Zebol, S.M. Pitson, Translocation of sphingosine kinase 1 to the plasma membrane is mediated by calcium- and integrin-binding protein 1, J. Biol. Chem. 285 (1) (2010) 483-492.

[229] H.J. Jun, H. Johnson, R.T. Bronson, S. de Feraudy, F. White, A. Charest, The oncogenic lung cancer fusion kinase CD74-ROS activates a novel invasiveness pathway through E-Syt1 phosphorylation, Cancer Res. 72 (15) (2012) 3764-3774.

[230] M.L. Knowlton, L.M. Selfors, C.N. Wrobel, T.L. Gu, B.A. Ballif, S.P. Gygi, R. Polakiewicz, J.S. Brugge, Profiling Y561-dependent and -independent substrates of CSF-1R in epithelial cells, PLoS One 5 (10) (2010) e13587.

[231] S.M. Davidson, M.G. Vander Heiden, Critical functions of the lysosome in Cancer biology, Annu. Rev. Pharmacol. Toxicol. 57 (2017) 481-507.

[232] B. Zhitomirsky, Y.G. Assaraf, Lysosomes as mediators of drug resistance in cancer, Drug Resist. Updat. 24 (2016) 23-33.

[233] C. Grimm, K. Bartel, A.M. Vollmar, M. Biel, Endolysosomal cation channels and Cancer-A link with great potential, Pharmaceuticals (Basel) 11 (1) (2018).

[234] O.N. Nguyen, C. Grimm, L.S. Schneider, Y.K. Chao, C. Atzberger, K. Bartel, A. Watermann, M. Ulrich, D. Mayr, C. Wahl-Schott, M. Biel, A.M. Vollmar, Twopore channel function is crucial for the migration of invasive Cancer cells, Cancer Res. 77 (6) (2017) 1427-1438.

[235] P. Faris, M. Shekha, D. Montagna, G. Guerra, F. Moccia, Endolysosomal Ca(2+) Signalling and Cancer Hallmarks: Two-Pore Channels on the Move, TRPML1 Lags Behind!, Cancers (Basel) 11 (1) (2018).

[236] M.B. Morelli, M. Nabissi, C. Amantini, D. Tomassoni, F. Rossi, C. Cardinali, M. Santoni, A. Arcella, M.A. Oliva, A. Santoni, C. Polidori, M.P. Mariani, G. Santoni, Overexpression of transient receptor potential mucolipin-2 ion channels in gliomas: role in tumor growth and progression, Oncotarget 7 (28) (2016) 43654-43668.

[237] A. Rimessi, V. Bezzerri, S. Patergnani, S. Marchi, G. Cabrini, P. Pinton, Mitochondrial Ca2 +-dependent NLRP3 activation exacerbates the Pseudomonas aeruginosa-driven inflammatory response in cystic fibrosis, Nat. Commun. 6 (2015) 6201.

[238] S. Paillusson, P. Gomez-Suaga, R. Stoica, D. Little, P. Gissen, M.J. Devine, W. Noble, D.P. Hanger, C.C.J. Miller, Alpha-Synuclein binds to the ER-mitochondria tethering protein VAPB to disrupt $\mathrm{Ca}(2+)$ homeostasis and 
mitochondrial ATP production, Acta Neuropathol. 134 (1) (2017) 129-149.

[239] S.C. Alford, Y. Ding, T. Simmen, R.E. Campbell, Dimerization-dependent green and yellow fluorescent proteins, ACS Synth. Biol. 1 (12) (2012) 569-575.

[240] A. Melcrova, S. Pokorna, S. Pullanchery, M. Kohagen, P. Jurkiewicz, M. Hof, P. Jungwirth, P.S. Cremer, L. Cwiklik, The complex nature of calcium cation interactions with phospholipid bilayers, Sci. Rep. 6 (2016) 38035.
[241] G.J. Fredericks, F.W. Hoffmann, A.H. Rose, H.J. Osterheld, F.M. Hess, F. Mercier, P.R. Hoffmann, Stable expression and function of the inositol 1,4,5-triphosphate receptor requires palmitoylation by a DHHC6/selenoprotein K complex, Proc. Natl. Acad. Sci. U. S. A. 111 (46) (2014) 16478-16483.

[242] P.J. Ko, S.J. Dixon, Protein palmitoylation and cancer, EMBO Rep. 19 (10) (2018). 